\title{
Análise da aplicação de indicadores alternativos ao Overall Equipment Effectiveness (OEE) na gestão do desempenho global de uma fábrica
}

\author{
Christianne Matias Busso ${ }^{\mathrm{a} *}$, Dario lkuo Miyake ${ }^{\mathrm{b}}$ \\ a*chrisbusso@usp.br, USP, Brasil \\ bdariomiy@usp.br, USP, Brasil
}

\begin{abstract}
Resumo
Embora a medição do Overall Equipment Effectiveness (OEE) seja uma prática de gestão industrial com crescente difusão, indicadores alternativos ao mesmo têm sido propostos na literatura para tratar da avaliação do desempenho num nível mais global dos sistemas de produção. 0 objetivo deste artigo é de apresentar e analisar tais indicadores e explorar suas possibilidades de aplicação na busca de um aproveitamento efetivo da capacidade de produção. Inicialmente, é elaborado um quadro referencial para o enquadramento de indicadores que ampliam a abordagem de avaliação adotada pelo OEE. Para analisar o potencial de aplicação de indicadores que têm essa função, é desenvolvido um estudo de caso em uma empresa processadora de alimentos. 0 caso mostra que a aplicação de indicadores como o Overall Throughput Effectiveness (OTE) e o Overall Plant Effectiveness (OPE) pode tornar o diagnóstico de problemas de utilização da capacidade mais eficaz, além de induzir a integração da estratégia de produção com outras estratégias funcionais e, assim, promover uma gestão mais efetiva do desempenho global de uma fábrica.
\end{abstract}

Palavras-chave

OEE. OTE. OPE. Indicador de desempenho. Capacidade.

\section{Introdução}

0 mercado atual tem exigido cada vez mais que as empresas de manufatura disponibilizem seus produtos com qualidade, rapidez, flexibilidade, confiabilidade e menor custo. Para Gagnon (1999), uma forma de conduzir a gestão estratégica das operações procurando atender esses objetivos seria baseá-la na visão dos recursos de produção. Esses recursos envolvem decisões como: desenvolvimento de produtos, tecnologia a ser utilizada, organização da mão de obra, planejamento da capacidade e configuração das instalações, entre outras. Fleischer, Weismann e Niggeschmidt (2006) reforçam que a competitividade das empresas de manufatura depende da disponibilidade e produtividade de seus recursos de produção.

A necessidade de priorizar a racionalização do uso de um recurso ou outro depende do tipo de processo e produto que a empresa oferece ao mercado: empresas mais intensivas em mão de obra precisam investir mais na capacitação e motivação dos recursos humanos; empresas de produção em massa precisam buscar elevada eficiência na utilização de equipamentos e recursos humanos bem como no consumo de insumos materiais; já as empresas de processo contínuo precisam assegurar fluxo altamente previsível por meio de tecnologias intensivas em capital (SLACK et al., 2002).

Nos casos da manufatura de produção em massa e em processo contínuo, é fundamental assegurar elevada disponibilidade e confiabilidade dos equipamentos. Para promover o desempenho da empresa pela competente utilização de seus recursos de produção, Jonsson e Lesshammar (1999) afirmam que é necessário estabelecer um sistema integrado de avaliação do desempenho global da manufatura (Overall Manufacturing Performance). Quando as causas de perdas na utilização da capacidade de 
produção são identificadas, esforços para eliminá-las ou reduzi-las podem ser empreendidos.

Segundo ljungberg (1998), houve uma gradual evolução na forma de avaliação das perdas que impactam na disponibilidade dos equipamentos. Na década de 1970, a ênfase incidia na avaliação das perdas de produção dos ativos fixos, que eram divididas em falhas mecânicas, elétricas, eletrônicas e hidráulicas. Já na década de 1980, procurou-se avaliar os obstáculos para produção classificando-os como causas técnicas e causas organizacionais. $\mathrm{Na}$ década de 1990, acentuou-se a preocupação em medir as perdas por paradas classificando-as como planejadas ou não planejadas.

É importante observar que mesmo quando os recursos de produção estão disponíveis, a sua utilização pode ocorrer de forma ineficiente. Nesse sentido, Staudt, Coelho e Gonçalvez (2011) colocam que a geração de refugos e a necessidade de retrabalhos são desprezadas por muitas empresas na análise de sua capacidade, mas que no planejamento da capacidade real necessária para se atender a demanda é fundamental considerar que elas também consomem tempo de recursos produtivos.

0 advento da filosofia de manutenção produtiva total (TPM) sob os auspícios do Japan Institute of Plant Maintenance (JIPM) trouxe a noção de que é necessário desenvolver uma visão mais holística do sistema de manufatura e que para isso é fundamental estabelecer uma forma mais abrangente de medir o aproveitamento da capacidade produtiva. 0 Overall Equipment Effectiveness (OEE) que mede a utilização efetiva da capacidade dos equipamentos foi então proposto como um indicador que cumpre essa função de controle gerencial (NAKAJIMA, 1989; LJUNGBERG, 1998).

0 indicador do OEE tem sido amplamente utilizado nas indústrias de manufatura no diagnóstico de seu sistema produtivo e direcionamento das ações de melhoria contínua, notadamente nas organizações que utilizam modelos gerenciais como Total Quality Management (TQM), World Class Manufacturing (WCM), seis sigma e produção enxuta, além do próprio TPM (BOHORIS et al., 1995; TSAROUHAS, 2007; WEE; WU, 2009; GIBBONS; BURGESS, 2010). Sua aplicação tem sido difundida em diversos setores industriais, dentre os quais se destacam o automobilístico, semicondutores e as indústrias de processo. Esse indicador promove uma visão ampliada da vida útil dos equipamentos e assume que as condições de uso destes é basicamente influenciada pela sua disponibilidade, desempenho e qualidade de conformidade. Existem guias e padrões referenciais para sua medição e análise que podem servir como base para permitir a comparação dos resultados de diferentes plantas num dado setor industrial (RON; ROODA, 2005).

Jeong e Phillips (2001) salientam que a abordagem de medição do OEE é muito importante em indústrias intensivas em capital, já que esse indicador não avalia somente a utilização, e demanda a identificação e análise das perdas escondidas. Ao preconizar a medição dessas perdas que podem ocorrer mesmo quando os equipamentos estão operando - falta de qualidade do produto final e variação do tempo de ciclo do processo -, o OEE promove a análise dos problemas e o tratamento da causa raiz de modo a tornar as ações de melhoria do processo mais efetivas e aumentar o aproveitamento da capacidade dos equipamentos. Ljungberg (1998) afirmam que, em muitas empresas, antes de qualquer intervenção de melhoria, é comum que o valor de OEE seja baixo. Numa pesquisa de campo realizada por esses autores constatou-se um valor médio de cerca de 55\%.

Bamber et al. (2003) descrevem que o OEE é utilizado para diferentes fins, não se restringindo à eliminação de perdas e melhoria da qualidade. Ele serve como medida de benchmarking inicial para comparações dentro de uma planta, ajuda a entender diferenças entre linhas de produção pela comparação de seus resultados e permite identificar a máquina que deve ser o foco dos esforços de TPM de modo a racionalizar os investimentos e a operação dos demais recursos produtivos. Adicionalmente, a medição do OEE permite identificar distúrbios crônicos em equipamentos e, assim, promove a busca de melhorias de processo e o aumento da sua vida útil.

Não obstante o OEE tenha se tornado um indicador de vasta utilização pela simplicidade e clareza de sua conceituação, esse indicador revela limitações como a dificuldade em definir e medir certos dados para seu cálculo como tempo de ciclo do processo e pequenas paradas (RON; ROODA, 2005).

Autores como ljungberg (1998), Bamber et al. (2003) e Braglia, Frosolini e Zammori (2009) concordam que o OEE é um ótimo indicador para medir a eficiência de uma única máquina, mas que não seria suficiente para direcionar a melhoria global do processo produtivo quando este envolve diversos equipamentos inter-relacionados. Muthiah e Huang (2007) acrescentam que a conceituação do OEE não atende o propósito central de um sistema integrado de medição da manufatura, que é o de medir a eficiência de toda a fábrica. Diante da necessidade de aprimorar a medição do desempenho da manufatura num nível mais global, Schmenner e Vollmann apud Jonsson e Lesshammar (1999) afirmam que as empresas precisam buscar indicadores que melhor reflitam os resultados de toda a manufatura indo além daqueles contemplados pelo OEE. 
Uma questão gerencial relevante levantada por Ljungberg (1998) diz respeito às responsabilidades sobre as perdas. As perdas consideradas pelo OEE são as comumente associadas às áreas de produção ou de manutenção. Para Jeong e Phillips (2001), a definição original de OEE não é adequada para indústrias intensivas em capital, que buscam a maior utilização possivel dos equipamentos, pois esse indicador não considera perdas devido às paradas para manutenção preventiva e o não aproveitamento da capacidade em períodos não programáveis como feriados e turnos inativos. Assim, pela limitação dos tipos de perdas que considera, a avaliação pelo OEE pode causar distorções, como atribuir à produção a responsabilidade por perdas que não são controladas por ela. Perdas decorrentes de problemas de embalagens do fornecedor ou por reinicialização de processo, após uma queda brusca de energia, são exemplos de falhas que têm como causa raiz problemas externos a uma fábrica.

Por essas razões, a forma de aplicação do OEE está sujeita a adaptações para se adequar ao contexto do que deve ser medido. Muchiri e Pintelon (2008) colocam que na literatura são encontradas derivações do termo OEE conforme a natureza de sua aplicação. Quando considerado em relação à eficiência de fábrica, é denominado como Overall Factory Effectiveness (OFE), em relação à planta, como Overall Plant Effectiveness (OPE) ou Overall Asset Effectiveness (OAE), e em relação à medição das saídas de produto como Overall Throughput Effectiveness (OTE). Há ainda variantes como o Total Equipment Effectiveness Performance (TEEP), que amplia a classificação das perdas, e o Production Equipment Effectiveness (PEE), que considera que os diferentes tipos de perdas devem ser ponderados de forma diferente numa avaliação global.

Jeong e Phillips (2001) destacam que, dessa forma, as empresas têm utilizado alternativas ao OEE que incorporam a medição de perdas por razões não consideradas na definição original de OEE como, por exemplo, tempos não programados, paradas planejadas de manutenção, e realização de testes de produto, bem como decisões resultantes da gestão do negócio. Isso também decorre da necessidade de caracterizar o objeto da medição como uma máquina, um conjunto de máquinas, uma linha, uma planta ou um negócio. As empresas têm interesse de adotar métricas que se adequam melhor à sua realidade, utilizá-las para melhorar o aproveitamento da capacidade de seus equipamentos e, assim, assegurar o retorno do capital investido.

Diante do exposto, o presente artigo tem como objetivo analisar as possibilidades de aplicação de indicadores alternativos ao OEE como ferramenta de gestão por empresas de manufatura que buscam melhores resultados para o seu negócio e explorar como tal esforço pode ser efetivamente conduzido pela gerência. Com esse segundo ponto pretende-se cobrir uma lacuna na literatura tendo em vista o fato de que os trabalhos que propõem a aplicação de indicadores alternativos ao OEE, sob uma perspectiva mais global, têm se limitado a somente definir seu modelo de cálculo (OECHSNER et al., 2003) ou exemplificar sua forma de cálculo, mas assumindo dados teóricos para uma dada situação (RAOUF, 1994; HÖGFELDT, 2005), por meio de simulação computacional (NACHIAPPAN; ANANTHARAMAN, 2006; MUTHIAH; HUANG; MAHADEVAN, 2008), ou considerando dados médios (visão estática) para um caso de sistema de produção (CHAND; SHIRVANI, 2000; MUTHIAH; HUANG, 2007; MUCHIRI; PINTELON, 2008; BRAGLIA; FROSOLINI; ZAMMORI, 2009), sem tratar a questão de sua efetiva introdução e aplicação gerencial por uma organização.

0 artigo está organizado conforme segue. Com base em revisão da literatura, a seção seguinte discute a concepção original do OEE, analisa suas limitações de aplicação e apresenta indicadores alternativos para a avaliação do desempenho global da manufatura. Para facilitar o entendimento da forma de aplicação desses indicadores, na seção 3, o artigo contribui elaborando uma proposta de enquadramento geral dos mesmos. Na seção 4, é delineado o método de pesquisa utilizado no desenvolvimento de um estudo de caso que teve como propósito investigar como uma indústria de processo desdobrou esforços para implementar efetivamente indicadores mais abrangentes que o OEE na estruturação de um sistema de avaliação e melhoria do desempenho global em uma fábrica, e na sua posterior extensão para a medição do desempenho global da manufatura. 0 caso estudado é apresentado na seção 5 e analisado na seção 6 , contribuindo para elucidar o potencial de uso gerencial dos indicadores adotados na busca de melhores resultados para o negócio. Finalmente, as conclusões e recomendações para trabalhos futuros são apresentadas na seção 7 .

\section{Revisão da literatura}

\subsection{O OEE como indicador de desempenho}

A implementação do TPM é baseada em três conceitos centrais: maximização da eficiência do equipamento, manutenção autônoma realizada por operadores e organização de pequenos grupos de melhoria (LUUNGBERG, 1998). Nesse contexto, o OEE tem sido amplamente utilizado como indicador para medição do desempenho global do(s) equipamento(s) na manufatura que, ao estruturar a análise das 
perdas de aproveitamento de sua capacidade, ajuda a direcionar os esforços de melhoria contínua dos pequenos grupos (JONSSON; LESHAMMAR, 1999) e a avaliar o progresso na implementação do TPM na organização (JEONG; PHILLIPS, 2001). Como métrica de uso gerencial, o OEE tem sido adotado principalmente por indústrias que precisam assegurar elevada disponibilidade de seus equipamentos.

0 cálculo do OEE é realizado pela identificação de 6 tipos básicos de perdas, que são agrupados nas seguintes 3 classes, conforme ilustra a Figura 1.

A. Perdas de disponibilidade

A1. Paradas que provocam falha de equipamento

A2. Paradas para setup ou ajustes

B. Perdas de desempenho

B1. Pequenas paradas ou interrupções devido ao mau funcionamento do equipamento

B2. Redução da velocidade do equipamento devido a alguma anomalia que o faça operar com tempo de ciclo maior que o tempo padronizado

C. Defeitos e perdas de qualidade

\section{C1. Produção defeituosa ou retrabalho}

C2. Perdas de start-up ou perdas ocasionadas no início da produção devido aos ajustes para estabilização do equipamento.

0 OEE pode ser entendido como uma relação entre o tempo em que houve agregação de valor ao produto e o tempo de carregamento de máquina, ou seja, descontando-se as perdas de disponibilidade (A), perdas de desempenho (B) e perdas de qualidade (C). Para o seu cálculo, é adotada a Equação 1, que considera as definições dadas à direita na Figura 1 para os componentes referentes à disponibilidade (D), desempenho (P) e qualidade (Q).

$\mathrm{OEE}=\mathrm{D} \times \mathrm{P} \times \mathrm{Q}$

Alternativamente, o OEE pode ser calculado pela razão entre o volume de produção correspondente ao tempo com valor agregado e ao tempo de carregamento, conforme a Equação 2 (KWON; LEE, 2004).

$$
\text { OEE }=\frac{\begin{array}{c}
\text { Total de } \\
\text { Produtos Bons }
\end{array}}{\begin{array}{l}
\text { Tempo de } \\
\text { Carregamento }
\end{array} \times \begin{array}{l}
\text { Capacidade de Produção } \\
\text { Teórica por Hora }
\end{array}}
$$

A eliminação ou redução dos tipos de perdas identificados por esse indicador requer que, além da manutenção e produção, outras áreas como qualidade e engenharia colaborem no desenvolvimento de esforços de melhoria de modo mais sistêmico.

Nakajima (1988) propõe que ações de melhoria sejam desdobradas a partir da análise do indicador OEE por meio de ferramentas de gestão da qualidade como o gráfico de Pareto e o diagrama de causa e efeito: o primeiro permite identificar os tipos de perdas que têm maior impacto no resultado do OEE e o segundo ajuda a organizar a investigação do real motivo da ocorrência dos mesmos facilitando sua identificação e eliminação. Nesse esforço de análise e melhoria, Bamber et al. (2003) ressaltam a importância do envolvimento de grupos multifuncionais que detenham uma adequada combinação de conhecimentos e habilidades sobre todo o processo considerado, observando que a adoção do OEE promove o alinhamento de visões na investigação e isso possibilita à gerência delegar-lhes

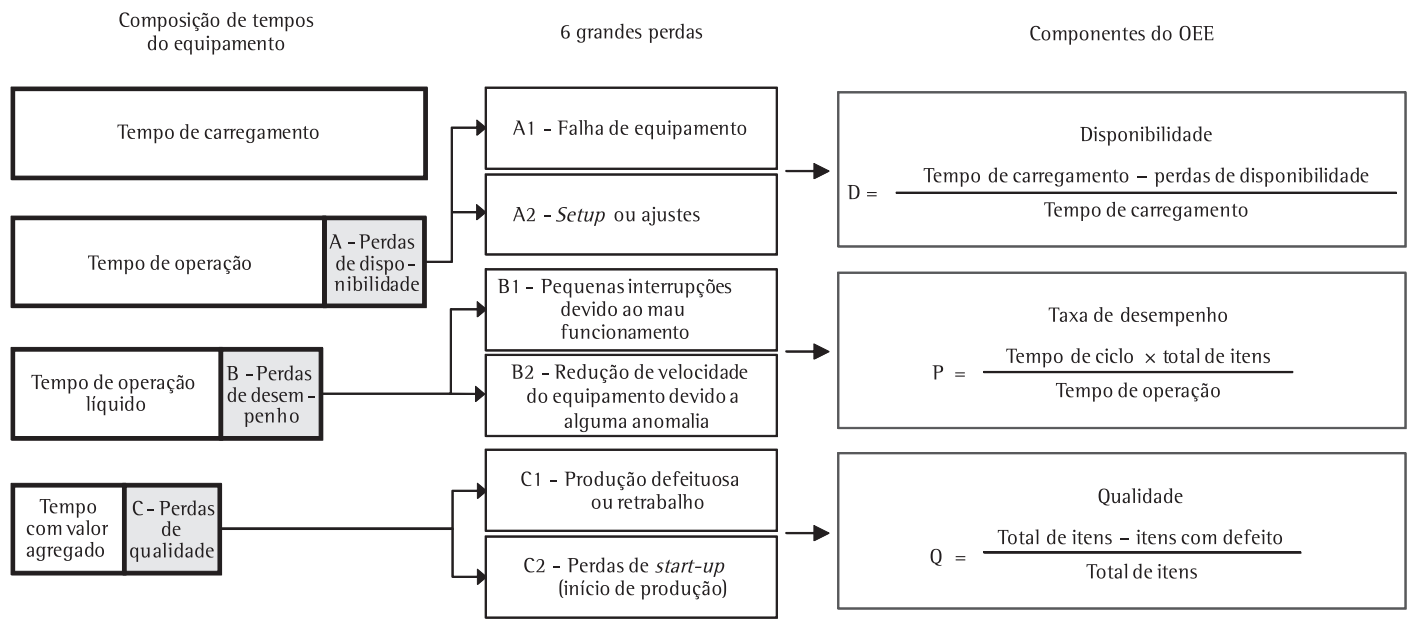

Figura 1. Estrutura das 6 perdas de tempo observadas no indicador de OEE (adaptada de NACHIAPPA; ANANTHARAMAN, 2006; BRAGLIA; FROSOLINI; ZAMMORI, 2009). 
maior responsabilidade e autoridade para implementar as ações de melhoria.

A utilização do OEE tem sido relevante na avaliação do retorno de investimentos realizados no âmbito de programas de melhoria como os baseados no TPM. Para Chand e Shirvani (2000), a efetividade de um sistema de manutenção bem como das práticas de gestão de equipamentos pode ser avaliada medindo-se o desempenho global dos equipamentos por meio do OEE. Segundo Kwon e Lee (2004), é possivel contabilizar como o aumento do OEE resultante dos esforços de melhoria contínua para aumentar a disponibilidade de equipamentos reverte-se em redução do custo de manufatura e aumento incremental na margem de lucro.

\subsection{Limitações do OEE como indicador de desempenho global da manufatura}

$\mathrm{Na}$ literatura, são encontrados diversos questionamentos sobre a aplicação do OEE como indicador de desempenho global da manufatura. Jonsson e Lesshammar (1999) advertem que a maioria das empresas utiliza de forma incorreta os indicadores de desempenho ou falham na escolha de tais indicadores. Segundo esses autores, um sistema integrado de avaliação do desempenho global da manufatura deve contemplar o que deve ser medido sob as perspectivas da estratégia, da orientação ao fluxo, da eficiência interna e da eficácia externa. Adicionalmente, apontam duas características sobre o modo como o desempenho global da manufatura deve ser medido, quais sejam: o potencial de sua utilização no direcionamento de melhorias e a simplicidade/facilidade de acesso/atualização. Assumindo a premissa de que, provavelmente, não existe um sistema de medição que seja uma panaceia que satisfaça plenamente todas essas dimensões e características, esses autores apontam a necessidade de cada organização desenvolver seu próprio sistema de forma dinâmica e interativa.

A análise sintetizada no Quadro 1 revela que o OEE, como indicador, não atende todas as dimensões e características consideradas (JONSSON; LESSHAMMAR, 1999). No que diz respeito à perspectiva da orientação ao fluxo, o OEE não considera de forma integrada as atividades, processos e funções encontrados ao longo da cadeia de produção. Em relação à eficiência interna, revela uma visão limitada por contemplar somente as paradas causadas por problemas de manutenção e produção. Além disso, vale salientar que uma grande fragilidade do OEE é a sua falta de visão da eficácia externa, o que o impede de refletir o que ocorre na cadeia de valor identificando perdas que afetam 0 fluxo de processo, entre o recebimento do pedido e sua entrega ao cliente. Isso dificulta a percepção de trade-offs entre o objetivo da manufatura e o de outras áreas que interagem com a mesma na busca dos resultados do negócio como um todo.

A conceituação básica do OEE fornece uma boa forma de medir a eficiência de uma única máquina (BRAGLIA; FROSOLINI; ZAMMORI, 2009). Contudo, a simples extensão da sua aplicação convencional à avaliação de um sistema de produção com mais máquinas não seria suficiente para direcionar sua melhoria global, considerando sistemicamente os possíveis impactos num âmbito mais amplo.

0 Quadro 2 resume os principais benefícios e limitações da utilização do OEE como indicador de desempenho global da manufatura apontados na literatura.

Assim, faz-se necessário buscar indicadores que não somente meçam o desempenho de um equipamento ou uma área, mas que também possibilitem avaliar

Quadro 1. OEE $\times$ Dimensões e Características de um Sistema de Medição do Desempenho Global (Adaptada de JONSSON; LESSHAMMAR, 1999)

\begin{tabular}{|c|c|c|}
\hline & Definição & Avaliação do OEE \\
\hline $\begin{array}{l}\text { Estratégia de } \\
\text { Manufatura }\end{array}$ & $\begin{array}{c}\text { Traduz as estratégias corporativas e de negócio em todos os } \\
\text { níveis da organização }\end{array}$ & $\begin{array}{l}\text { Quando aplicado junto as metodologias de } \\
\text { TPM/TQM, permite definição de objetivos } \\
\text { comuns e estratégias por toda a organização. }\end{array}$ \\
\hline Orientação do Fluxo & $\begin{array}{l}\text { Contempla funções, atividades e processos de forma integrada ao } \\
\text { longo da cadeia de produção. }\end{array}$ & Não contemplada pelo OEE. \\
\hline Eficiência Interna & $\begin{array}{l}\text { Permite medir e comparar a eficiência funcional internamente a } \\
\text { uma organização. }\end{array}$ & $\begin{array}{l}\text { OEE é uma medida simples, mas abrangente. } \\
\text { Porém nem sempre permite ser comparado entre } \\
\text { diferentes áreas ou funções. }\end{array}$ \\
\hline Eficácia Externa & $\begin{array}{c}\text { Contempla medições externas, inclusive o nível de satisfação dos } \\
\text { clientes. }\end{array}$ & Não contemplada pelo OEE. \\
\hline $\begin{array}{l}\text { Direcionador de } \\
\text { Melhoria }\end{array}$ & $\begin{array}{l}\text { Serve não somente para informar mas também para acionar } \\
\text { esforços de melhoria contínua. }\end{array}$ & $\begin{array}{c}\text { Oferece grande contribuição quando utilizado } \\
\text { como indicador de desempenho em processos de } \\
\text { melhoria contínua. }\end{array}$ \\
\hline Simples e Dinâmico & $\begin{array}{c}\text { Simples e fácil de entender, calcular e usar. Pode evoluir com } \\
\text { o tempo mediante revisões para se manter atualizado como } \\
\text { indicador. }\end{array}$ & $\begin{array}{l}\text { Foco no OEE, ao inves de diferentes medições } \\
\text { para eficiência interna, simplifica o sistema } \\
\text { de medição. Contudo, o OEE precisa ser } \\
\text { complementado por outras medições. }\end{array}$ \\
\hline
\end{tabular}


Quadro 2. Benefícios e limitações do OEE.

\begin{tabular}{|c|c|}
\hline Benefícios & Limitações \\
\hline $\begin{array}{l}\text { - Possibilita a análise de problemas de produção ou } \\
\text { manutenção e consequente atuação na causa raiz (JEONG; } \\
\text { PHILLIPS, 2001); } \\
\text { - Possibilita a identificação de máquinas que devem ser foco de } \\
\text { atividades de gestão da manutenção (BAMBER et al., 2003); } \\
\text { - Permite comparação interna entre as máquinas de uma } \\
\text { mesma planta (BAMBER et al., 2003); e } \\
\text { - Registros de paradas para identificação das perdas permitem } \\
\text { a complementação dos planos de manutenção já existentes } \\
\text { (CHAND; SHIRVANl, 2000). }\end{array}$ & $\begin{array}{l}\text { - Quando aplicado a um escopo maior que uma única máquina (linha } \\
\text { de produção ou planta), não direciona adequadamente as ações para } \\
\text { melhoria contínua (BRAGLIA; FROSOLINI; ZAMMORI, 2009); } \\
\text { - Não fornece visão sistêmica das perdas do negócio, pois não considera } \\
\text { interações além do equipamento (JONSSON; LESSHAMMAR, 1999); } \\
\text { - A utilização somente do OEE pode definir responsabilidades para a área de } \\
\text { produção que não necessariamente são da mesma (LJUNGBERG, 1998); e } \\
\text { - Dificuldade de reconhecer outras perdas com base na taxonomia das seis } \\
\text { grandes perdas do OEE (JEONG; PHILLIPS, 2001). }\end{array}$ \\
\hline
\end{tabular}

os impactos de sistemas maiores em sua cadeia de valor, que possam ser usados em comparações intra e interorganizações, que contemplem as necessidades dos clientes e que sejam simples de serem compreendidos, atualizados e utilizados em processos de melhoria contínua.

\subsection{Indicadores de desempenho alternativos ao OEE}

O OEE é amplamente aceito como medição primária para a fábrica que auxilia a avaliação dos equipamentos e que estabelece uma disciplina para melhoria. Porém, ao se restringir à medição do desempenho de equipamentos específicos e não abranger a interação com recursos relacionados, sua utilização acaba sendo confinada a um contexto local (MUTHIAH; HUANG, 2007).

Diferentes conceituações de indicadores que procuram suprir carências do OEE foram identificadas na literatura. Nas seções seguintes, elas são apresentadas divididas em dois grupos: 1) variantes do OEE que ampliam a abrangência do sistema de operações considerado e 2) indicadores que ampliam a classificação das perdas em relação à que o OEE por definição considera.

\subsubsection{Alternativas que ampliam a abrangência do sistema de operações}

Para esse tipo de indicadores, o objeto avaliado vai além de um equipamento isolado, o que implica em contemplar diferentes máquinas/processos e o modo como estes estão relacionados (e.g. se os equipamentos estão em série ou em paralelo).

Braglia, Frosolini e Zammori (2009) apresentam o conceito de Overall Equipment Effectiveness of a Manufacturing Line (OEEML). Trata-se de uma variação do OEE que, além das perdas de disponibilidade e qualidade, considera as perdas decorrentes de problemas de alimentação de matéria-prima na linha, as ineficiências do gargalo e as paradas planejadas de manutenção. 0 OEEML considera que, em uma linha de produção, há estoques entre suas etapas de processo e admite que a produção resultante depende do nível desses estoques. Em uma linha com baixo OEEML, quanto mais à jusante se encontrar a etapa de processo com o menor OEE, maior tende a ser o estoque acumulado antes da mesma. Quando o OEEML é alto, os materiais fluem melhor e o estoque na linha tende a ser baixo. Tais relações e efeitos não podem ser constatados somente pela consideração do OEE. Já em sistemas de manufatura em linha com dois ou mais equipamentos sem estoque intermediário significativo, Braglia, Frosolini e Zammori (2009) sugerem que a conceituação do OEE pode ser aproveitada, tomando-se como referência as limitações impostas pelas perdas na etapa gargalo do processo.

Chand e Shirvani (2000) propõem estender a aplicação do conceito de OEE para a avaliação de uma célula de produção/linha, considerando dados de saída de produtos conformes, tempo médio de ciclo e tempo de carregamento da célula/linha seguindo a lógica da Equação 2. Para facilitar sua distinção, neste trabalho esse indicador é denominado de OEEL (OEE de uma célula ou linha).

Nachiappan e Anantharaman (2006) propõem o cálculo do Overall Line Effectiveness (OLE), uma extensão do OEE para o cálculo do desempenho global da linha, que considera, além das 6 grandes perdas, as perdas relacionadas às paradas por manutenção planejada.

Para levar a ideia da medição pelo OEE ao nível de toda uma fábrica, existe a proposta do Overall Factory Effectiveness (OFE) - ou Plant OEE, como chamado por Högfeldt (2005) - de avaliar o desempenho global da mesma admitindo que isso resulte da interação de diferentes máquinas/processos e de decisões/ações tomadas por seus diversos sistemas e subsistemas (OECHSNER et al., 2003). Uma variante do OFE seria o Overall Throughput Effectiveness (OTE), que considera a forma de conexão existente entre os equipamentos. Muthiah e Huang (2007) sugerem que os subsistemas que constituem uma fábrica podem assumir quatro tipos básicos de 
configuração - equipamentos em série, em paralelo, montagem alimentada por múltiplos equipamentos e equipamento que fornece para vários outros -, sendo que no cálculo do OTE para cada tipo de subsistema é preciso observar como sua produção total é limitada pela capacidade dos recursos restritivos e ineficiências encontradas no percurso do fluxo produtivo. Isso vai além da abordagem simplificada de calcular um indicador global para um conjunto de equipamentos como uma média dos resultados individuais de cada equipamento, como se a ineficiência de cada um fosse independente das condições de operação dos demais. Muthiah e Huang (2007) e Muthiah, Huang e Mahadevan (2008) acrescentam que assim como a produção de equipamentos encadeados em série é limitada pelo equipamento-gargalo, para se obter o numerador global do OFE de uma fábrica é necessário identificar o subsistema-gargalo e verificar como seu OTE restringe as saídas finais.

Para facilitar a extensão do cálculo do OEE ao nível de uma fábrica, vale resgatar a ideia de confrontar o total de produtos bons entregues pela mesma com o total de produtos que teoricamente ela poderia ter produzido (OECHSNER et al., 2003; MUCHIRI; PINTELON, 2008), de modo análogo ao seu cálculo para um determinado equipamento usando a Equação 2.

A Figura 2 ilustra algumas possibilidades de ampliação das fronteiras do objeto de avaliação. A abrangência da avaliação baseada na conceituação do OEE pode ser estendida a sistemas de produção em linha dedicados a um produto ou a uma família de produtos similares (flow shop), mediante certas simplificações, mas preservando-se em grande parte sua perspectiva analítica original. Já para sistemas de produção sem padrões de fluxo bem definidos, como fábricas com características de job shop, a extrapolação da conceituação do OEE do nível micro de um equipamento para o nível macro da fábrica envolve uma complexidade muito maior e não é tratada neste trabalho.

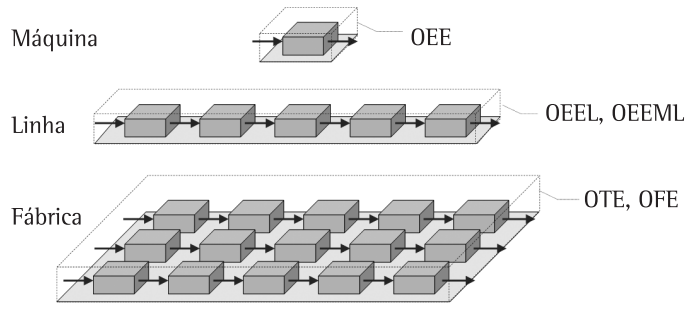

Figura 2. Variações do OEE conforme abrangência do sistema produtivo (elaborada pelos autores).

\subsubsection{Alternativas que ampliam a classificação de perdas}

Alternativas ao OEE também têm sido formuladas ampliando a classificação de perdas considerada na conceituação básica do OEE (Figura 1). Suzuki (1994) foi um dos primeiros a reconhecer que é preciso contemplar também a influência de fatores externos à fábrica, como suprimentos e vendas, que impedem a plena utilização de sua capacidade.

Ivancic (1998) apud Muchiri e Pintelon (2008) propôs uma variante do OEE chamada de Total Equipment Effectiveness Performance (TEEP) que considera as paradas planejadas no cálculo do indicador. 0 TEEP mostra mais claramente como a função manutenção está impactando na produtividade da manufatura, pois as paradas planejadas de manutenção são estimadas com base no tempo médio entre falhas (MTBF) e no tempo médio de reparo (MTTR). Dessa forma o TEEP indica como melhores práticas de manutenção que reduzem 0 MTTR ou que aumentam o MTBF resultam num melhor aproveitamento de equipamentos. A aplicação do TEEP foi concebida para se avaliar a produtividade no nivel de um equipamento, mas pode ser estendida à avaliação de um sistema maior como uma planta de processos ou fábrica do tipo flow shop que pode ser tratada como uma única entidade de produção.

Outra variante do OEE é o Production Equipment Effectiveness (PEE) apresentado por Raouf (1994), que propõe medi-lo de forma diferente conforme o tipo de produção: no caso de produção discreta, considera os mesmos três componentes do OEE (disponibilidade, desempenho e qualidade), mas no caso de processo contínuo inclui componentes adicionais para considerar outros tipos de perdas como falta de demanda. Neste trabalho, essas variantes são chamadas respectivamente de PEE-disc e PEE-cont, sendo que ambas, diferentemente do OEE, admitem que seus componentes afetam o resultado final com pesos distintos.

Mais recentemente, Braglia, Frosolini e Zammori (2009) definiram o Total Overall Equipment Effectiveness (TOEE) como um indicador que considera o efeito das paradas denominadas de perdas independentes do equipamento, tais como perdas por falta de operador, por falta de suprimento, e pela realização do controle de qualidade, que não dependem das condições de funcionamento do equipamento em si.

Finalmente, vale destacar as alternativas do Overall Plant Effectiveness (OPE) e Overall Asset Effectiveness (OAE) que, além das perdas consideradas pelo OEE, consideram perdas provocadas por outras causas além da alçada dos gestores responsáveis pela operação do processo produtivo, quais sejam: 
- Causas comerciais: falta de demanda ou baixa demanda;

- Problemas logísticos externos: falta de fornecimento, problemas com transporte, queda de energia etc;

- Regulamentações ambientais: quotas de produção estabelecidas em função de limites para emissão de dióxido de carbono etc;

- Causas naturais: condições climáticas adversas, desastres como tempestades e furacões; e

- Causas relacionadas com a gestão do negócio que afetam a fábrica (estoques, logística interna, segurança, investimentos em novos produtos etc.).

Uma diferença entre o OPE e o OAE é a forma de cálculo, sendo que o OAE não é calculado com dados em tempo, mas em unidades de produto. Segundo Muchiri e Pintelon (2008), ambos são indicadores ainda pouco discutidos na literatura que carecem de uma definição mais consagrada.

A Figura 3 ilustra possíveis extensões à classificação de perdas considerada pelo OEE. Nota-se que o escopo ampliado das perdas consideradas por certos indicadores alternativos ao OEE pode contemplar o efeito de perdas causadas por áreas de suporte, outras áreas da cadeia de valor e mesmo por decisões estratégicas da organização, proporcionando uma visão mais sistêmica do desempenho que a produção pode alcançar.

\section{Análise da literatura discutida e proposta de enquadramento das alternativas de indicadores de desempenho global da manufatura}

Nesta seção, os indicadores identificados na revisão da literatura (OEE, TEEP, PEE-disc, PEE-cont, OPE, OAE, OFE, OTE, OEEML, OEEL, TOEE, OLE) são comparados e organizados de modo a facilitar a identificação de modelos mais apropriados para se avaliar e gerenciar o desempenho global da manufatura de forma mais integrada. Para isso, foi elaborado um quadro referencial que apresenta o contexto em que esses indicadores podem ser aplicados em função da abrangência do sistema produtivo que propõem avaliar e da amplitude da classificação dos tipos de paradas que consideram. Na Figura 4 é proposto um enquadramento dos indicadores considerados, fornecendo uma visão comparativa da abordagem de medição dos mesmos e mostrando como o escopo por eles considerado varia do mais restrito ao mais abrangente. As quadrículas com fundo mais escuro delimitam o contexto primário de aplicação desses indicadores e suas possíveis extensões.

A seguir, as alternativas de indicador levantadas são analisadas quanto às suas propriedades. Para conduzir essa análise comparativa, foi utilizada a relação de dimensões e características proposta por

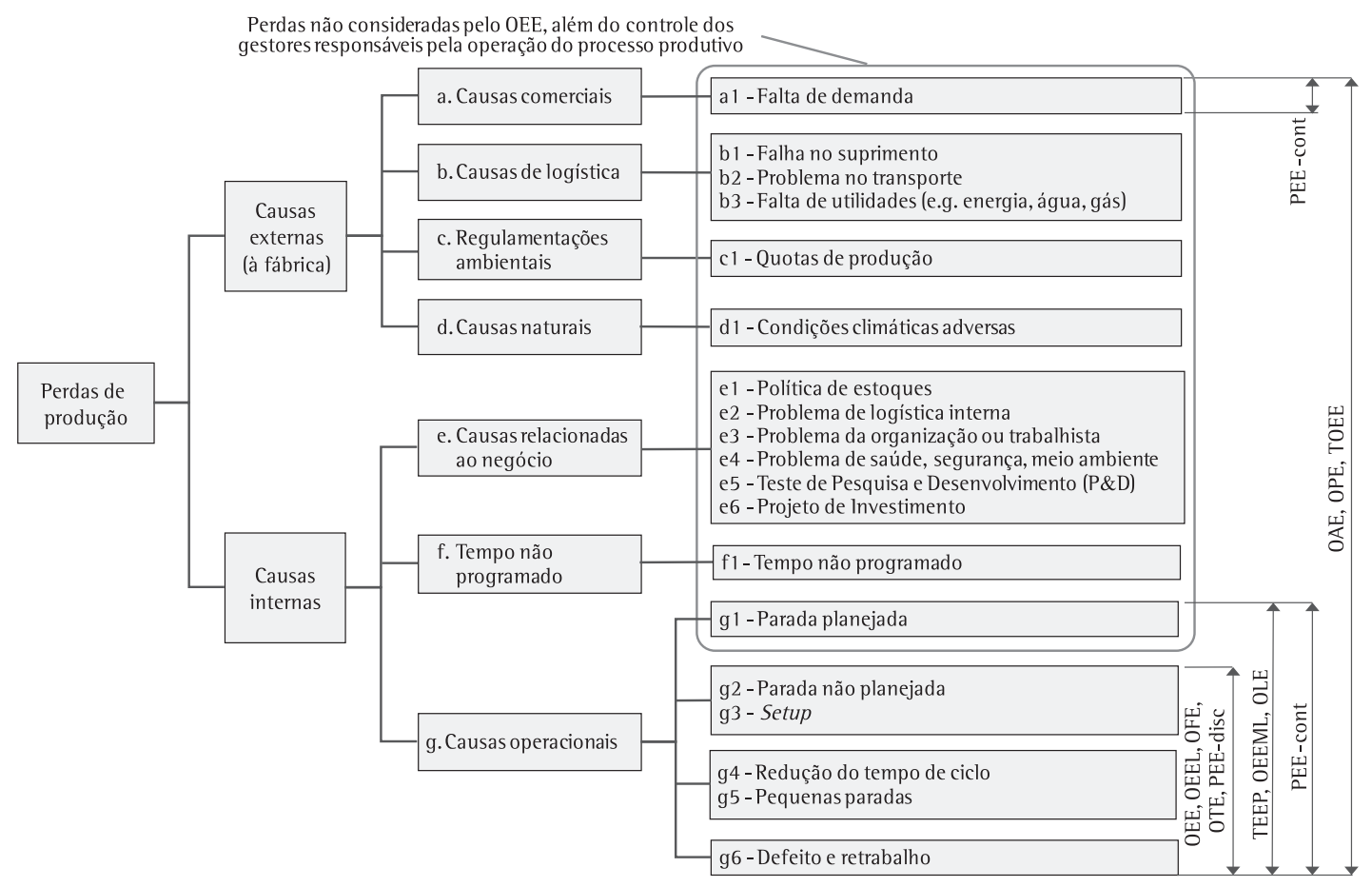

Figura 3. Classificação das perdas de produção para avaliação do desempenho da manufatura (adaptada de MUCHIRI; PINTELON, 2008). 

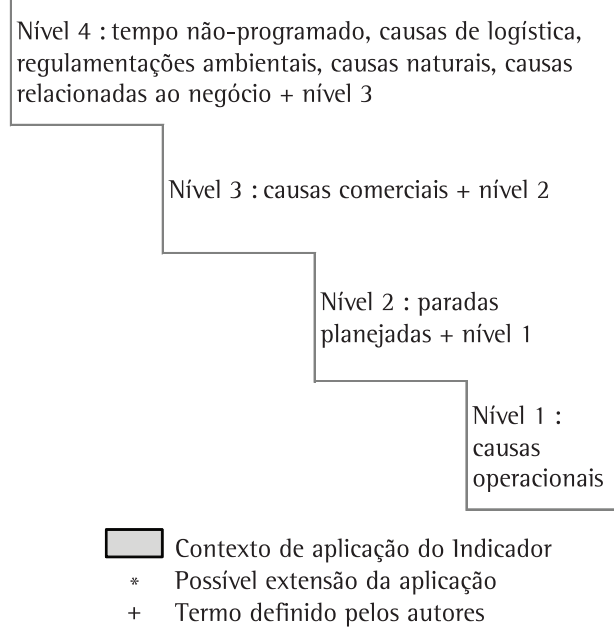

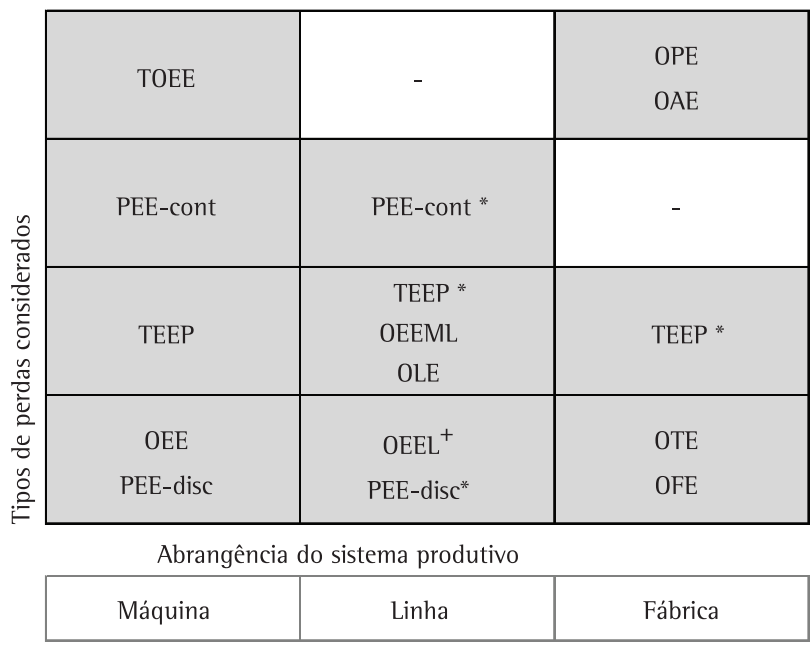

Figura 4. OEE e indicadores alternativos conforme a classificação dos tipos de paradas e abrangência do sistema produtivo que considera (elaborada pelos autores).

Johnsson e Lesshammar (2009), de forma análoga à análise estruturada do OEE apresentada no Quadro 1.

\section{a) Estratégia}

Em relação ao alinhamento do indicador à estratégia de negócio, observa-se que, assim como o OEE, os indicadores OFE, OTE, OLE, OEEML, TEEP e PEE-disc podem traduzir as estratégias corporativas quando amparado por algum programa gerencial que os sustente. É possível que os indicadores PEE-cont, TOEE, OPE e OAE reflitam impactos causados por fatores externos à fábrica como comportamento do mercado e estratégias seguidas por outras partes da cadeia produtiva.

\section{b) Orientação ao fluxo}

Com exceção do OEE, TEEP e PEE-disc, as demais alternativas permitem contemplar o fluxo produtivo por outras atividades e funções ao longo da cadeia. As variações do OEE em termos de abrangência do sistema produtivo não permitem uma visão mais ampla do fluxo produtivo, pois se limitam a avaliar diferentes equipamentos somente no âmbito da manufatura. Já as variações que ampliam a classificação de perdas como o PEE-cont e, em especial, o TOEE, OPE e OAE permitem avaliar como decisões tomadas ou mesmo restrições preexistentes em outras partes da cadeia, como na área comercial e/ou na logística, afetam no aproveitamento da capacidade na área produtiva.

\section{c) Eficiência interna}

Todos os indicadores apresentados, assim como o OEE, auxiliam o controle da produção e podem ser úteis na comparação da eficiência de diferentes funções ou áreas da empresa. 0 PEE-cont, TOEE, OPE e OAE, por considerar um número maior de tipos de perdas, são os indicadores que oferecem mais possibilidades de comparação dos impactos que diferentes áreas de suporte à fábrica causam na eficiência. Esses indicadores, por exemplo, permitem detectar como paradas excessivas para realização de testes pela área de desenvolvimento de novos produtos podem comprometer a eficiência ao diminuir a disponibilidade para produção.

\section{d) Eficácia externa}

Nenhum dos indicadores enumerados chega a abordar os clientes para medir seu nível de satisfação. O PEE-cont, TOEE, OPE e OAE, ao medirem o tempo de parada por falta de demanda, podem sugerir um possivel problema de aceitação do produto pelo mercado, porém uma demanda fraca pode se dar por outros motivos, tais como estratégias de venda ou de marketing ineficazes.

\section{e) Direcionador de melhoria}

Todos os indicadores enumerados podem contribuir com o processo de melhoria contínua, desde que não sejam utilizados somente como informação, mas como mais uma ferramenta para que os grupos de melhoria contínua possam atuar, conforme enfatizado por Nakajima (1988).

\section{f) Simples e dinâmico}

0 cálculo de indicadores ampliando o escopo do sistema produtivo requer a consideração de um número maior de equipamentos e do layout como os mesmos estão dispostos (se estão em série ou em paralelo), o que tende a dificultar o cálculo e requerer revisões sempre que houver alguma mudança no sistema. Já a ampliação da classificação de perdas implica basicamente em manter a forma de cálculo dos tipos básicos de perdas e adicionar os valores das novas classes de perdas. Jeong e Phillips (2001) colocam que uma das grandes dificuldades da medição do OEE, bem como de outros indicadores, é a coleta de dados: qualquer erro pode invalidar a medição. 
Atualmente, diversos sistemas computadorizados já efetuam essa coleta de forma automática, reduzindo o risco de erros e simplificando o processo de medição.

0 Quadro 3 resume a análise comparativa dos indicadores enumerados e fornece uma visão de como o sistema de medição pode ser aprimorado adotando-se indicadores com escopo menos restrito que o OEE.

\section{Método de pesquisa}

Uma vez analisada e organizada a relação de indicadores alternativos ao OEE identificados na literatura, o estudo teve prosseguimento com uma pesquisa empírica para investigar seu potencial de efetiva aplicação como ferramenta de avaliação e melhoria do desempenho global da manufatura. Embora o início da disseminação do OEE remonte à década de 1980, as iniciativas para estender sua aplicação enxergando a manufatura inserida no contexto do negócio é uma tendência recente. Assim, este estudo caracteriza-se pela realização de uma pesquisa empírica de um fenômeno contemporâneo, em seu contexto real, com o propósito de buscar um entendimento amplo da natureza e complexidade dos esforços requeridos para tornar a aplicação da conceituação do OEE efetiva na gestão do desempenho global da manufatura em uma organização, sendo portanto direcionado por uma questão central de pesquisa do tipo "como": como conduzir tal iniciativa gerencial? Essas circunstâncias são pertinentes com as que, segundo Meredith (1998), justificam a adoção do método do estudo de caso. Optou-se por realizar um estudo de caso único profundo para favorecer a obtenção de um conhecimento detalhado do fenômeno considerado.

0 caso selecionado refere-se a uma iniciativa empreendida por uma fábrica de processo contínuo que ao se ver compelida a melhorar seu processo de planejamento e controle da produção, com o objetivo de aumentar o volume de produção e as vendas, constatou que teria de rever o sistema de medição de desempenho que estava baseado na estrutura do OEE. A possibilidade de investigar as limitações desse sistema e as mudanças realizadas para aprimorá-lo motivou sua seleção como unidade de análise e a condução de um estudo com perspectiva longitudinal.

A pesquisa consistiu numa análise da condução dessa iniciativa de 2008 a 2010. A coleta de dados foi concentrada em duas etapas. A primeira etapa foi realizada em janeiro de 2009 com o propósito de investigar o desenvolvimento inicial da iniciativa no período de abril a dezembro de $2008 \mathrm{em}$ que a adequação do sistema de medição e avaliação do desempenho estava sendo questionada. Neste período, os esforços estavam mobilizados para rever esse sistema de modo que não ficasse limitado ao controle das perdas medidas pelo OEE e assim ampliar o escopo do processo de melhoria direcionado pelo mesmo. Embora o objetivo da iniciativa fosse de melhorar o desempenho global da fábrica, neste período, as ações estavam concentradas no aumento da produção de uma linha específica. Foi então realizada uma visita à fábrica tomada como unidade de análise para conhecer o sistema de medição do desempenho em desenvolvimento, a dinâmica de análise dos resultados gerados pelo mesmo e a forma como as ações de controle e melhoria vinham sendo desdobradas no âmbito da linha em questão. Como essa iniciativa

Quadro 3. Comparação de indicadores vis-à-vis dimensões e características de um sistema de medição do desempenho global.

\begin{tabular}{|c|c|c|c|c|c|c|c|c|c|c|}
\hline & & OEE & OEEL & $\begin{array}{l}\text { OTE e } \\
\text { OFE }\end{array}$ & $\begin{array}{l}\text { OEEML e } \\
\text { OLE }\end{array}$ & TEEP & PEE-disc & PEE-cont & TOEE & OPE e OAE \\
\hline \multirow{4}{*}{ 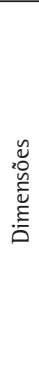 } & Estratégia & \multicolumn{6}{|c|}{ Atende quando atrelado a algum programa de melhoria } & $\begin{array}{c}\text { Reflete } \\
\text { alguma } \\
\text { estratégia } \\
\text { referente à } \\
\text { demanda }\end{array}$ & \multicolumn{2}{|c|}{$\begin{array}{l}\text { Pode refletir estratégias } \\
\text { referentes à demanda, } \\
\text { P\&D, meio ambiente e } \\
\text { outros fatores }\end{array}$} \\
\hline & $\begin{array}{l}\text { Orientação ao } \\
\quad \text { Fluxo }\end{array}$ & Não considera & \multicolumn{3}{|c|}{$\begin{array}{l}\text { Reflete condições do fluxo no nível } \\
\text { da manufatura }\end{array}$} & \multicolumn{2}{|c|}{ Não considera } & \multicolumn{3}{|c|}{$\begin{array}{l}\text { Capta a influência das áreas de apoio } \\
\text { no fluxo de manufatura }\end{array}$} \\
\hline & $\begin{array}{l}\text { Eficiência } \\
\text { Interna }\end{array}$ & \multicolumn{6}{|c|}{ Nem sempre permite comparação } & \multicolumn{3}{|c|}{$\begin{array}{l}\text { Oferece mais possibilidades de } \\
\text { comparação }\end{array}$} \\
\hline & $\begin{array}{l}\text { Eficácia } \\
\text { Externa }\end{array}$ & \multicolumn{6}{|c|}{ Não considera } & \multicolumn{3}{|c|}{$\begin{array}{l}\text { Pode captar quando a falta de } \\
\text { demanda estiver relacionada ao nível de } \\
\text { satisfação dos clientes }\end{array}$} \\
\hline
\end{tabular}

Direcionador Contribui desde que aproveitado sistematicamente pela organização como ferramenta do processo de melhoria contínua de Melhoria Simplifica a $\quad$ Pode requerer revisão caso medição, mas ocorra mudança no layout $\begin{array}{lcc}\text { Simples e } & \text { precisa ser } & \text { dos equipamentos e tornar a } \\ \text { Dinâmico } & \text { complementado } & \text { medição mais complexa. Precisa }\end{array}$ $\begin{array}{ccc}\text { Dinâmico } & \begin{array}{c}\text { complementado } \\ \text { com outras }\end{array} & \begin{array}{c}\text { medição mais complexa. Precisa } \\ \text { ser complementado com outras }\end{array}\end{array}$ medições medições

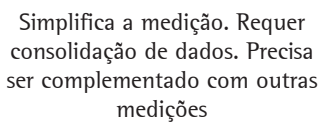

Simplifica a medição. Requer consolidação de dados. Precisa ser complementado com outras medições

Simplifica

Simplifica a medição.

a medição Requer maior consolidação de dados. 
envolvia um grupo de gestores da fábrica e das áreas envolvidas, foram entrevistados seus principais componentes, quais sejam: os responsáveis pela produção, manutenção, qualidade e melhoria contínua na unidade, e representantes das áreas de pesquisa e desenvolvimento (P\&D), marketing, comercial e programação e controle da produção (PCP), além do coordenador de melhoria contínua corporativo.

A segunda etapa de coleta de dados foi realizada em fevereiro de 2011 e teve como propósito investigar a ampliação do sistema de medição do desempenho global para o âmbito da manufatura como um todo, incluindo, além da fábrica, as áreas de apoio à produção. Para isso, foi realizada uma segunda visita à fábrica para entrevistas e observações.

A coleta de dados em duas etapas possibilitou obter uma visão da evolução do sistema de medição do desempenho global em desenvolvimento. Conforme recomenda Miguel (2010), o desenvolvimento de cada etapa do caso foi guiado por um protocolo. Os protocolos de pesquisa utilizados na condução e controle dessas etapas são apresentados no Anexo 1. Nas duas visitas, a entrevista do grupo de pessoas envolvidas no sistema de medição investigado foi realizada por meio de uma reunião com duração de aproximadamente duas horas, seguindo o roteiro semiestruturado apresentado no item "Procedimento de coleta de dados no local" dos protocolos de pesquisa. Em cada visita, após a reunião, o coordenador de melhoria contínua corporativo forneceu uma explicação mais detalhada do método de medição dos indicadores de desempenho que foram adotados. A participação dos entrevistados abordados nas 25 atividades enumeradas nos protocolos é apresentada no Anexo 2. 0 fato de um dos autores fazer parte do quadro de colaboradores desta empresa e atuar na área de melhoria de processos facilitou acesso a muitos dados primários.

Em estudos de caso é importante que a coleta de dados seja realizada de diversas maneiras pela combinação de diferentes procedimentos e múltiplas fontes para que a triangulação reforce a análise e o julgamento do pesquisador (SAKAKIBARA et al., 1990). Assim, na discussão de questões de natureza qualitativa durante as reuniões, procurou-se sistematicamente obter uma resposta com a qual dois ou mais participantes concordassem. Os dados coletados nessas reuniões foram complementados por observações feitas nas visitas às instalações, levantamento de dados históricos utilizados na medição dos indicadores de desempenho focados e análise documental tanto de atas de reunião do grupo responsável pela avaliação dos resultados desses indicadores como de atas de reuniões de acompanhamento de projetos de melhoria desdobrados no contexto desse caso.

\section{Estudo de caso: desenvolvimento de indicadores de desempenho global da manufatura}

\subsection{Caracterização da empresa}

A empresa do caso estudado é uma multinacional americana que atua no setor de industrialização de alimentos, voltada a produtos direcionados ao consumidor final. A unidade a que se refere o caso é uma fábrica localizada na região Sul do país, operada por cerca de 200 funcionários, que tem como produto principal os derivados à base de óleo hidrogenado.

Nessa unidade, o processo de produção é caracterizado por dois tipos de processo: a preparação é executada em bateladas e o envase/embalagem do produto ocorre num processo contínuo bastante automatizado, no qual a interferência humana se limita ao abastecimento de potes, tampas e embalagens secundárias. 0 processo de envase é realizado por 4 linhas (L1, L2, L3, L4) que se diferenciam pelo tipo de produto e tamanho da embalagem. Como é um processo crítico nesse ramo de negócio, sua operação precisa ser rigorosamente controlada para se buscar o pleno aproveitamento de sua capacidade e assegurar a competitividade do produto em custo. Por esse motivo, esse processo constitui o foco dos esforços de melhoria contínua.

0 desenvolvimento do sistema de avaliação do desempenho global na unidade de análise foi iniciado em 2008 e se insere no bojo de uma ação corporativa desdobrada a partir de um projeto denominado "Mais Produção" (MP), que teve como objetivo viabilizar um aumento de produção (volume em toneladas de margarina) para acompanhar a tendência de crescimento do mercado.

Para avaliar os resultados da manufatura, a gerência optou por inicialmente focar as perdas contempladas na medição do OEE, ou seja, as perdas de disponibilidade, de desempenho e de qualidade. Essa decisão foi motivada pelo elevado número de horas paradas por causas operacionais que vinham sendo registradas pelo serviço de manutenção.

\subsection{Da introdução do OEE à aplicação do OPEL}

Na unidade de análise, cada linha de produção é composta de 3 equipamentos em série nos quais o OEE pode ser medido separadamente. Contudo, como o fluxo em cada linha é contínuo e unidirecional, sua vazão é limitada pela capacidade do equipamentogargalo. Portanto, a empresa optou por medir primariamente o OEEL em cada linha tomando 
como base as condições em seu gargalo, que é o equipamento de envase do produto. Para o cálculo do OEEL a empresa adotou a Equação 2, considerando dados da produção total da linha, o tempo de carregamento do equipamento-gargalo e a capacidade de produção teórica do equipamento-gargalo. Estes dados são extraídos de uma base alimentada por um sistema informatizado de apontamento de paradas que discrimina a duração e o motivo delas, por linha.

No início do primeiro período, para implementar a gestão do desempenho da unidade com base na avaliação do OEEL, foi estabelecido um grupo multifuncional composto por responsáveis pela produção, qualidade e manutenção. Esse grupo optou por desenvolver uma prática geral de monitoramento do desempenho da fábrica e realização de melhorias visando ao aumento de seu volume de produção, focando seus esforços inicialmente numa linha piloto, e para isso selecionou a $\mathrm{L} 2$.

A evolução do OEEL da L2 durante o primeiro período é apresentada na Figura 5. Os dados levantados para o cálculo dos valores de OEEL estão tabelados no Anexo 3. Observa-se que houve quatro fases distintas. Na fase 1 foi introduzida a utilização do OEEL como indicador de desempenho global das linhas e deu-se início à geração de um histórico para poder identificar as principais causas de perdas. A análise da natureza das paradas identificadas nessa fase revelou que algumas causas não consideradas no cálculo do OEEL, como as mostradas a seguir, eram responsáveis por parcela significativa das paradas:

- Perdas por paradas planejadas (g1) por causas como manutenção preventiva e limpeza de linha que representavam cerca de $17,6 \%$ do tempo total de paradas;

- Perdas por outras causas além do controle dos gestores responsáveis pela operação das linhas, como as paradas por falta de demanda (a1) - embora a unidade opere em regime de 7 dias por semana, 24 horas por dia, não havia demanda suficiente para ocupar todo o tempo de produção disponivel - e por testes de $\mathrm{P} \& \mathrm{D}(\mathrm{e} 5)$ que representavam cerca de $53,7 \%$ do tempo total de paradas.

De maneira geral, foram evidenciados que as causas que afetavam o OEEL como aquelas que geram perdas de disponibilidade (g2, g3), desempenho e qualidade representavam 29\% do tempo total de paradas e que as causas que provocavam paradas não consideradas pelo OEEL (a1, b3, e5, g1) representavam 71\% do tempo total de paradas, conforme mostra a Figura 6.

Na fase 2, o grupo multifuncional passou a se reunir semanalmente para avaliar os resultados do OEEL com base no gráfico de Pareto das principais paradas e, a partir de sua análise, disparar ações para eliminar as causas raízes dos problemas. Entre a semana 10 (em junho de 2008) e a semana 17 (em julho de 2008), houve uma sensível elevação do OEEL de 66\% para 80\%, como mostra a Figura 5,

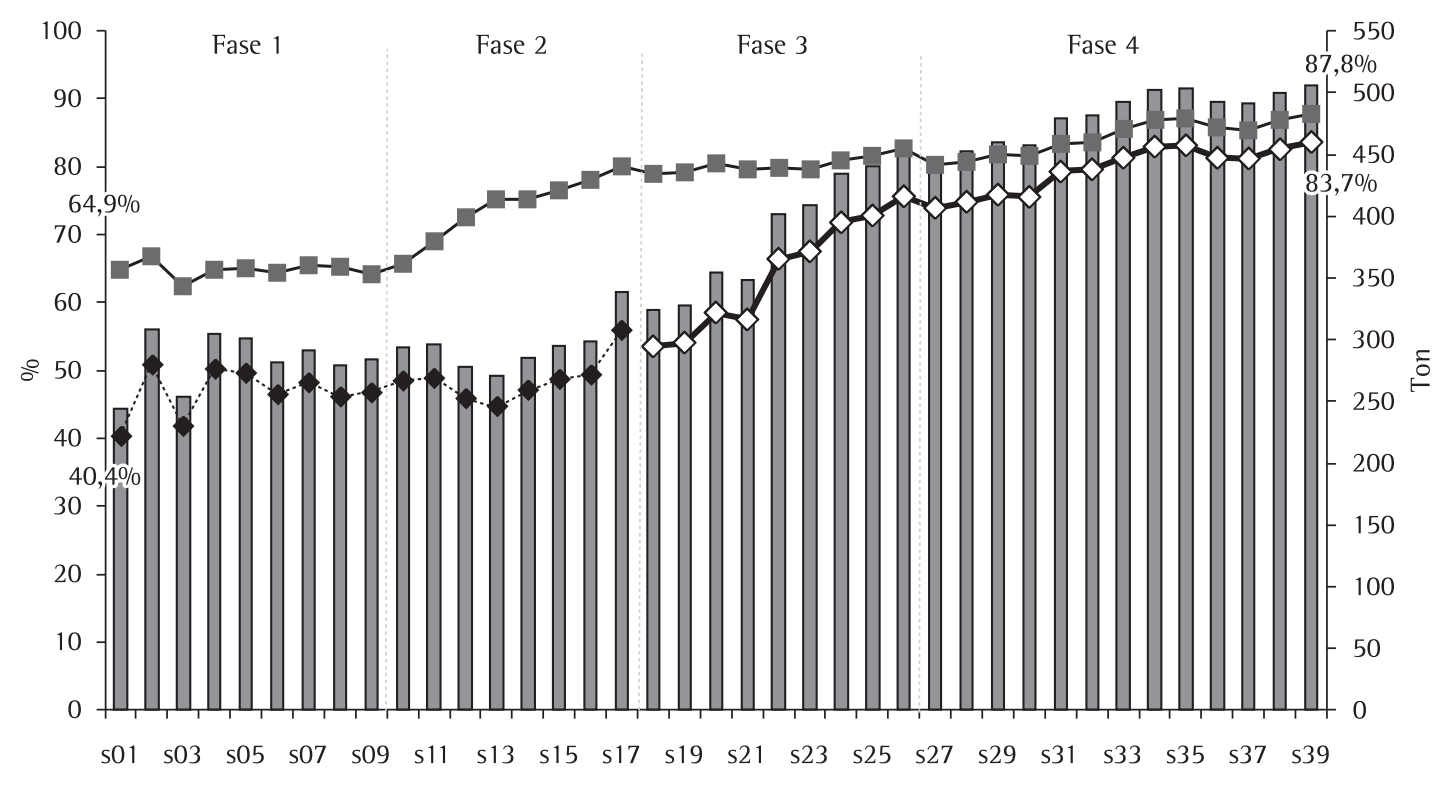

Semana

$\square$ Volume (ton) $\rightarrow$ OEEL $\prec$ Resultados da medição formal do OPEL

- ... Projeção de resultados de OPEL anteriores à medição formal

Figura 5. Evolução do OEEL e OPEL na L2 durante o primeiro período em 2008. 
sobretudo pela via da redução das perdas de disponibilidade. Para isso foram cruciais as ações realizadas pela equipe de melhoria da manufatura junto aos principais dispositivos do equipamento de envase que causavam paradas não planejadas - colocador de tampas com aba mole e o termoselador -, conforme indica a Figura 7 e o acompanhamento do grupo multifuncional para a sustentação do resultado.

Contudo, mesmo assim, a unidade não atingiu as metas de produção para acompanhar o crescimento do mercado. Ainda na fase 2, o grupo multifuncional detectou que somente as ações para elevação do OEEL poderiam não ser suficientes para alcançar incrementos adicionais significativos no volume de produção devido à magnitude das perdas causadas por fatores que estavam fora da alçada da área operacional. Uma análise de Pareto das paradas registradas na fase 1 confirmou que somente os responsáveis pela operação das linhas não teriam como atuar para assegurar o incremento de produção necessário, pois as principais causas dessas perdas que impediam o pleno aproveitamento da capacidade de produção eram as seguintes:

- Falta de demanda (a1): 45\% do tempo total em que a produção esteve parada foi devido à falta de vendas;

- Limpeza de linha (g1): embora obrigatória para atendimento às normas de segurança alimentar,

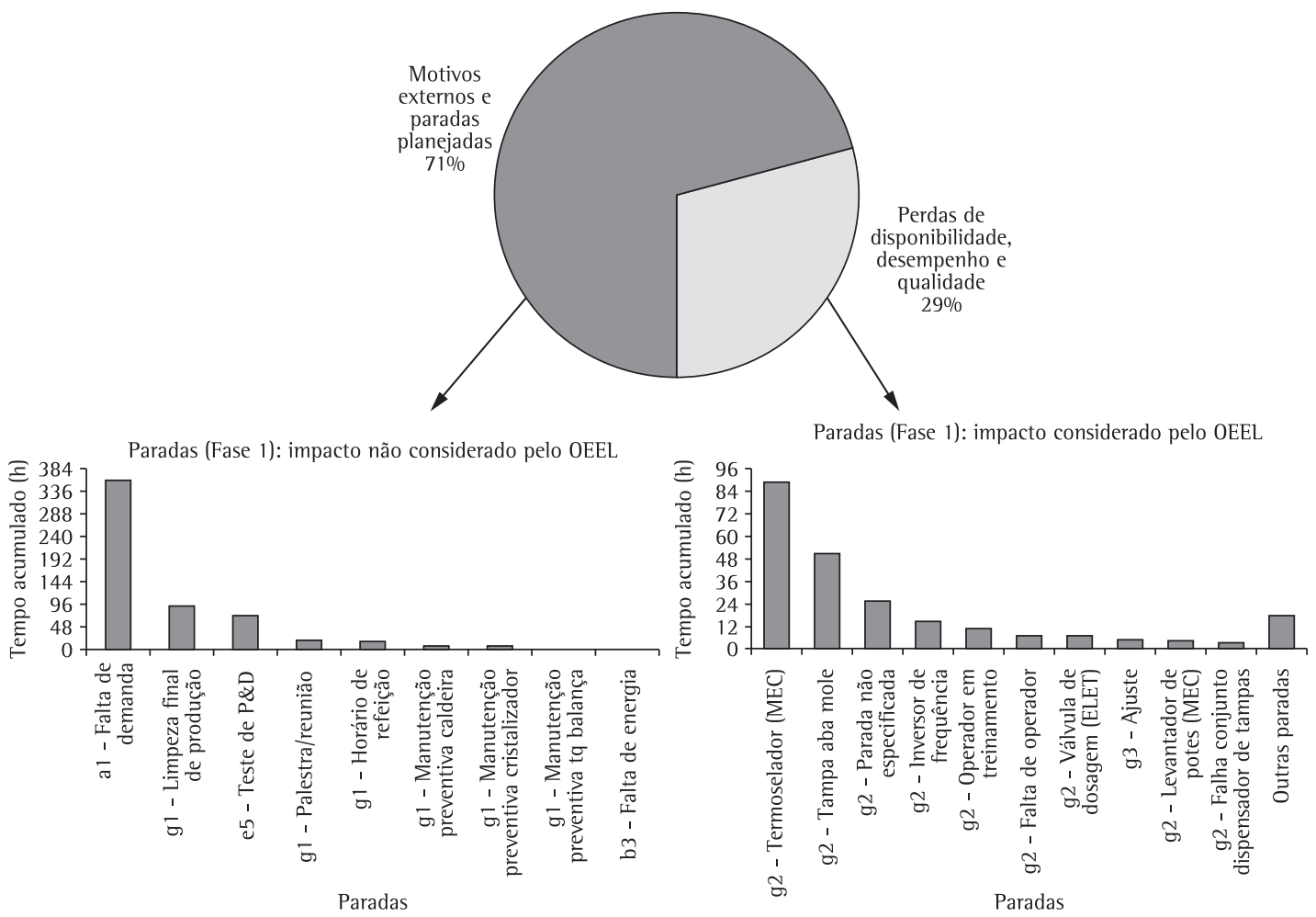

Figura 6. Estratificação das paradas registradas na fase 1.

Evolução dos tempos de paradas por fase: Termoselador (g2)

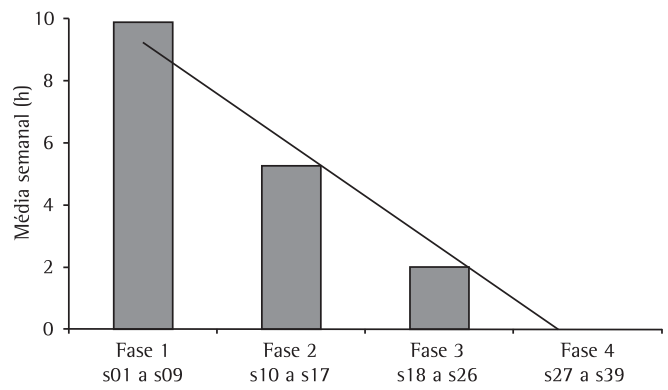

Evolução dos tempos de paradas por fase: Tampa aba mole (g2)

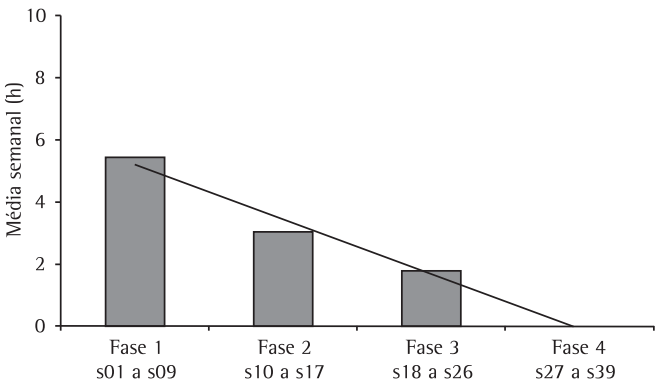

Figura 7. Evolução das principais paradas que impactam no OEEL durante o primeiro período. 
como não estava otimizada, o tempo para sua realização representava $11,4 \%$ do tempo total de paradas causando uma redução de disponibilidade maior que a prevista; e

- Teste de P\&D (e5): 8,7\% do tempo total de paradas era causado por testes realizados pela área de P\&D que, embora fundamentais para o lançamento de novos produtos, também subtraem disponibilidade de tempo para produção efetiva e, portanto, precisam ser muito bem programados.

Considerando a capacidade de produção da L2 (3,6 t/h) e analisando a evolução das perdas nessa linha (ver Anexo 3), observa-se que o volume de produção perdido devido às perdas de disponibilidade, desempenho e qualidade baixou de uma média de 153 t por semana (42,6 horas perdidas por semana), na fase 1 , para uma média de $104 \mathrm{t}$ por semana (28,8 horas perdidas por semana) na fase 2 . Já as perdas por paradas planejadas e outras causas fora da responsabilidade dos gestores da área operacional, somadas, foram responsáveis por uma perda de volume de produção maior, que se manteve em torno de 187 t por semana (51,9 horas perdidas por semana) nas fases 1 e 2 .

Assim, os responsáveis das áreas relacionadas aos fatores causadores de perdas externos à operação (P\&D, marketing, comercial e PCP) foram agregados ao grupo multifuncional inicial (produção, manutenção e qualidade), marcando o início da fase 3.

0 grupo ampliado avançou no entendimento do que seria necessário para atingir o objetivo final de obter significativo aumento de produção da fábrica, tendo sido esclarecido que isso não dependeria somente da redução das perdas de disponibilidade, desempenho e qualidade, mas também de ações direcionadas à melhoria do desempenho integrado de toda a manufatura pelo engajamento das áreas de apoio à produção em esforços de redução de paradas por falta de demanda, falha no suprimento e falha na programação de produção e testes, entre outras causas.

Isso motivou a gerência a passar a medir também as perdas não computadas pelo OEE e OEEL, visando atuar no controle das mesmas com o objetivo de buscar um volume de produção ainda maior. Decidiu-se então adotar a abordagem de medição mais ampla proposta pelo OPE. Embora esse indicador tenha sido concebido para a avaliação do desempenho de toda a manufatura sob a perspectiva da estratégia de negócio (MUCHIRI; PINTELON, 2008), na unidade em questão a gerência optou por inicialmente considerá-lo no âmbito intermediário de uma linha de produção. Assim, neste estudo, o indicador assim aplicado é denominado de OPEL para distingui-lo de sua aplicação no âmbito global da manufatura.
Na fase 3, o grupo multifuncional ampliado se reuniu diariamente para avaliar os indicadores de OEEL, OPEL e volume de produção. Sempre que uma meta diária não era atingida, o grupo analisava os problemas ocorridos, identificava suas causas e estabelecia ações para reduzir as perdas relacionadas. 0 desdobramento dessas ações foi sistematicamente acompanhado para garantir a sua realização. Os gerentes e diretores interessados na evolução dos esforços que buscavam melhores resultados para o negócio passaram a ser informados por meio de relatórios diários sobre os ganhos obtidos e ações que precisavam contar com maior apoio da liderança.

A medição conjunta do OEEL e do OPEL permitiu que análises e tomadas de decisão de nível mais estratégico envolvendo a cadeia de valor do produto pudessem ser realizadas. As ações tomadas para evitar paradas de produção por falta de capacidade de armazenagem ilustram bem isso. Esse problema é causado pela sazonalidade da demanda no mês que resulta no acúmulo de cerca de $60 \%$ do faturamento mensal na última semana. Para atender esse pico de vendas, o PCP procura antecipar a produção necessária distribuindo-a no decorrer das semanas anteriores de modo a racionalizar a ocupação da capacidade instalada. Contudo, frequentemente os armazéns ficavam lotados no meio do mês obrigando as linhas afetadas a parar, e isso comprometia o cumprimento do plano de produção e o pleno atendimento da carteira de pedidos. A medição pelo OPEL trouxe uma percepção mais clara do impacto causado por tais paradas. Um estudo conduzido pelo grupo multifuncional demonstrou ser mais vantajoso à empresa investir no aumento e adequação de seus armazéns do que conviver com as perdas e despesas (e. g. uso de armazéns externos, transportes extras de produto, ineficiências de partida de produção) causadas por tais paradas de produção.

A intensificação dos esforços de marketing que contribuíram para aumentar as vendas, a racionalização do procedimento de limpeza de linha sob a supervisão da engenharia e validação da área de qualidade, bem como a melhor programação dos testes de novos produtos e uma revisão das formulações do mix de produtos que reduziram o tempo das paradas de linha requeridas pelo $P \& D$, são também evidências de ações que puderam ser efetivadas com a implementação da avaliação balizada no OPEL. A análise do desempenho da manufatura sob uma visão mais sistêmica e a mobilização de um grupo multifuncional competente na sua gestão possibilitaram uma sensivel melhora nos resultados de OPEL (ver Figura 5), notadamente a partir da semana 18 (em agosto de 2008). Como indica a Figura 8, tais ações permitiram que a porcentagem do tempo total não aproveitado por causas não 

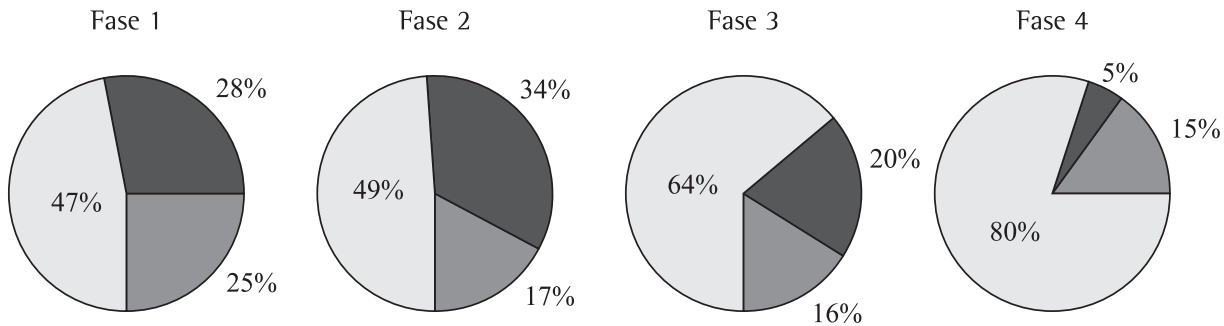

Tempo com valor agregado

Tempo das perdas de disponibilidade, desempenho e qualidade

Tempo das perdas que não impactam o OEEL

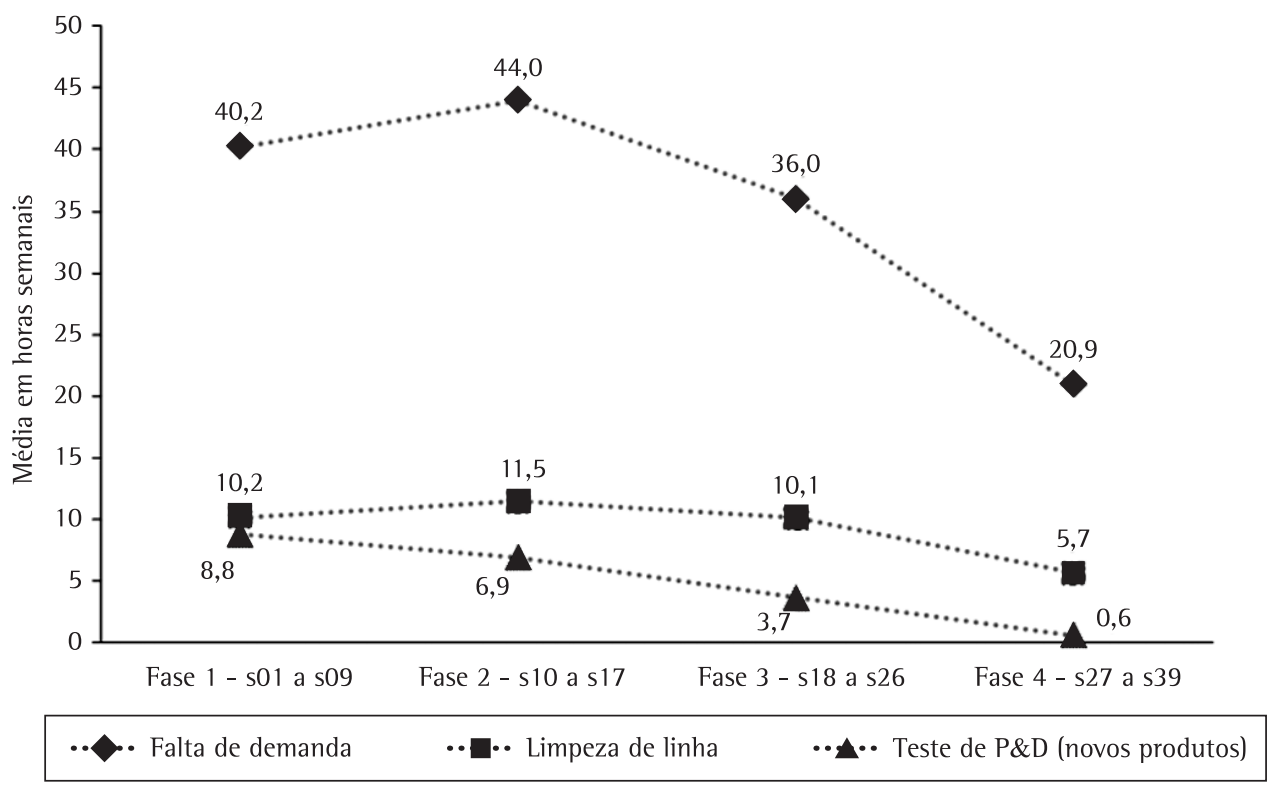

Figura 8. Evolução das principais paradas que não afetam o OEEL, mas medidas pelo OPEL.

consideradas pelo OEEL fosse reduzida de 14\% entre as fases 2 e 3 , e sua continuidade possibilitou atingir uma redução adicional de 15\% entre as fases 3 e 4, tornando-as responsáveis por grande parcela do salto registrado no OPEL.

Vale salientar que durante a fase 3 o grupo multifuncional concentrou-se na melhoria dos resultados de OPEL sem, contudo, descuidar-se de manter os resultados de OEEL no patamar relativamente elevado (cerca de $80 \%$ ) que havia alcançado no final da fase 2 , valendo-se da melhor integração da produção com as áreas de manutenção e qualidade.

$\mathrm{Na}$ fase 4 , conseguiu-se atingir um nível de OPEL superior a $80 \%$ na $\mathrm{L} 2$, indicando que seus maiores problemas haviam sido superados e, assim, as necessidades de intervenção do grupo multifuncional tornaram-se menos frequentes.

Essa abordagem de gestão mais integrada baseada no monitoramento do OEEL e OPEL foi reconhecida pela alta direção como meio-chave para racionalizar o aproveitamento da capacidade de produção das linhas, e assim ela decidiu estender sua aplicação à gestão das demais três linhas. Nessas linhas, a adoção do controle de perdas pela medição desses indicadores motivou também o desdobramento de ações efetivas visando um uso mais eficiente da capacidade de produção das mesmas.

\subsection{Evolução para aplicação do OPE e OTE}

Uma vez implantada a avaliação pelo OEEL e OPEL em todas as linhas, o desenvolvimento do sistema de avaliação de desempenho avançou para o estabelecimento da medição do desempenho global da fábrica e da manufatura adotando-se para isso, respectivamente, o OTE e o OPE como indicadores que, conforme sugerem Muchiri e Pintelon (2008), são alternativas para a avaliação do desempenho num nível mais global. Para o cálculo do OTE e do OPE na unidade objeto de estudo foram definidas, 
respectivamente, a Equação 3 - obtida da expansão da Equação 2 - e a Equação 4, conforme seguem abaixo, observando a existência de 4 linhas em paralelo $(n=4)$ :

$$
\begin{aligned}
& \text { OTE }=\frac{\sum_{i}^{n} V_{i}}{\sum_{i}^{n}\left(T C_{i} \times C p_{\mathrm{i}}\right)} \\
& \text { OPE }=\frac{\sum_{i}^{n} V_{i}}{\sum_{i}^{n}\left(T T_{i} \times C p_{\mathrm{i}}\right)}
\end{aligned}
$$

onde:

$\mathrm{V}_{\mathrm{i}}=$ volume produzido pela linha i no período;

$\mathrm{TC}_{\mathrm{i}}=$ tempo de carregamento da linha i no período (em horas);

$\mathrm{TT}_{\mathrm{i}}=$ tempo total da linha i no período (em horas);

$\mathrm{Cp}_{\mathrm{i}}=$ capacidade de produção por hora da linha i no período; e

$\mathrm{n}=$ número de linhas na fábrica.

Na segunda etapa de coleta de dados do presente trabalho, foram obtidos valores para esses indicadores medidos no período de julho de 2010 a dezembro de 2010. Na Figura 9 são apresentados os resultados de OTE da fábrica juntamente com os dados de OEEL de cada uma das quatro linhas nesse segundo período. Analogamente, na Figura 10 são apresentados os resultados de OPE de toda a manufatura juntamente com os dados de OPEL das linhas L1 a L4.

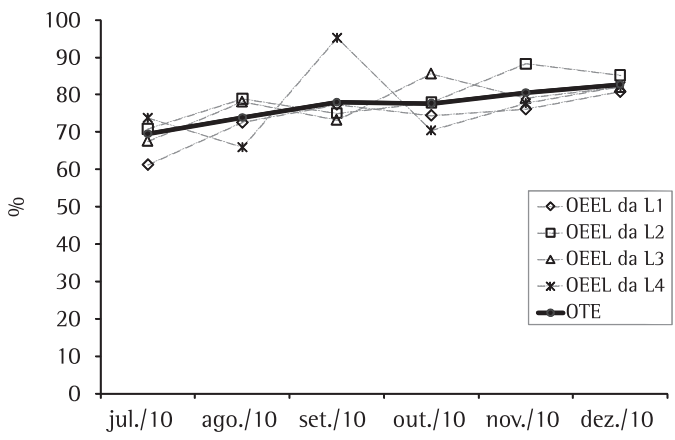

Figura 9. Evolução do OTE da fábrica e do OEEL das 4 linhas de produção no período de julho a dezembro de 2010 .

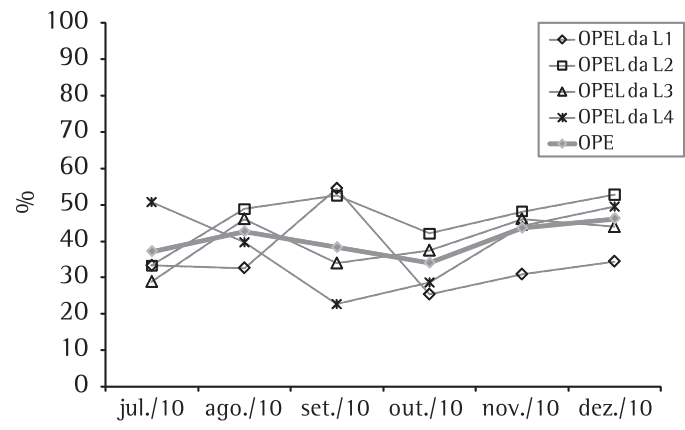

Figura 10. Evolução do OPE da manufatura e do OPEL das 4 linhas de produção no período de julho a dezembro de 2010.
No segundo período, observou-se que a manufatura como um todo operou com valores de OPE inferiores ao OPEL de cerca de $80 \%$ que a $\mathrm{L} 2$ havia atingido na fase 4 do primeiro período. Isso se deveu sobretudo a um aumento das paradas de linha por falta de demanda causado por estratégias comerciais que se mostraram infrutíferas. Já os resultados de OTE da fábrica variaram entre $70 \%$ e $80 \%$, tendo ficado acima do OEEL de cerca de 65\% observado na L2 na fase inicial do primeiro período.

Vale notar que para a $\mathrm{L} 2$, onde se iniciou a implementação do sistema de avaliação do desempenho global e que se encontra num estágio mais avançado de controle das perdas de produção, no segundo período, a média de seus resultados de OEEL medidos mensalmente $(79,4 \%)$ foi superior à média dos resultados de 0TE da fábrica $(77,1 \%)$. Além disso, a L2 foi mais bem-sucedida no controle dos impactos causados por perdas não consideradas pelo $\mathrm{OEE}$, tendo alcançado um valor médio de OPEL $(46,3 \%)$ maior que o valor médio de OPE de toda a manufatura $(40,3 \%)$.

\section{Análise do sistema de medição de desempenho global implantado}

\subsection{Análise do processo de implementação}

Somente a análise do OEEL de uma linha ou do OTE pode não possibilitar a identificação da principal causa de variação do volume produzido, respectivamente, pela linha ou pela fábrica a que se referem. No caso estudado, o total das perdas não consideradas pelo OEE como paradas planejadas e por outras causas além da alçada dos gestores responsáveis pela operação das linhas de produção era significativo, e a magnitude de seu impacto só pode ser medida pela adoção de indicadores que têm uma perspectiva mais ampla das possíveis perdas, como o OPEL e OPE.

0 caso revela que o entendimento coletivo do que consiste o desempenho global em uma organização é algo complexo e demanda substancial esforço de aprendizagem. Na Figura 11, é apresentada a trajetória percorrida no caso para o desenvolvimento do sistema de medição buscado pela empresa. No primeiro período, a abordagem de medição do OEE foi no início ampliada horizontalmente para passar a avaliar o desempenho de subsistemas como linhas e não de recursos elementares como máquinas. Em seguida, ela foi expandida verticalmente para abarcar perdas não consideradas pelo OEE. Uma vez estabelecida a medição do OEEL e OPEL no âmbito de cada linha, no segundo período, a abrangência do sistema a ser 

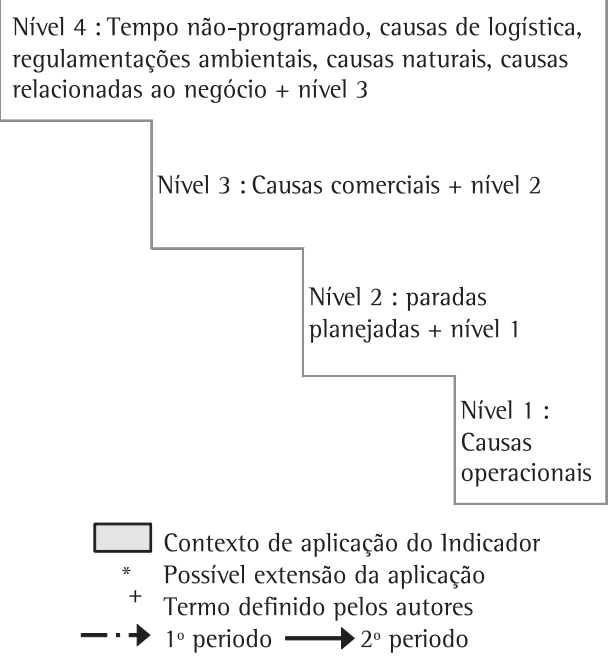

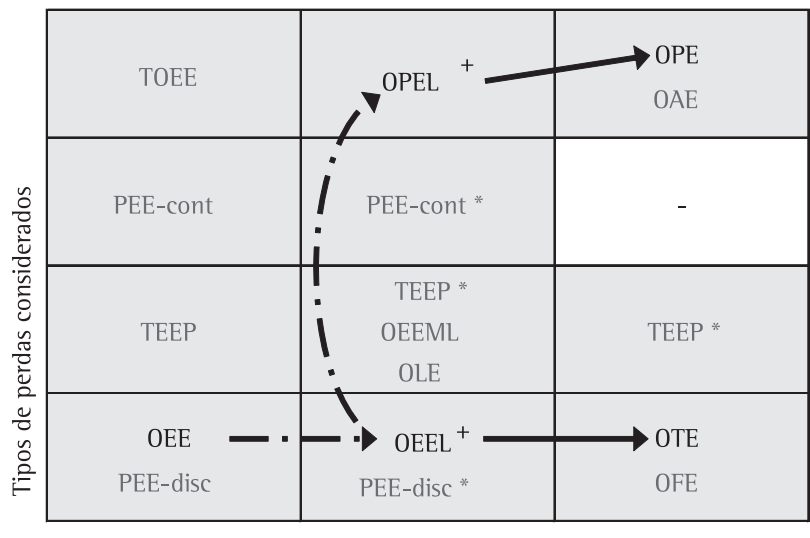

Abrangência do sistema produtivo

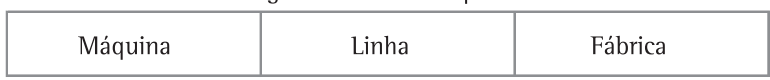

Figura 11. Indicadores aplicados pela unidade objeto de estudo (elaborada pelos autores).

avaliado foi então ampliada para passar a avaliar o desempenho no âmbito da fábrica e no âmbito global da manufatura pela adoção, respectivamente, do OTE e OPE.

\subsection{Análise dos indicadores implantados}

O OEE é um indicador relativamente restrito que considera somente a eficiência na utilização da capacidade de produção correspondente ao tempo de carregamento, mas isso não desmerece a sua aplicabilidade. No próprio caso estudado, as medições baseadas na conceituação do OEE foram suficientes para que, na fase 1 do primeiro período, a gerência pudesse estabelecer uma referência inicial para a eficiência produtiva de uma linha de produção e, na fase 2, conseguisse direcionar esforços de redução das perdas operacionais incrementando o OEEL em cerca de 14\% na linha piloto. Assim sendo, quando é preciso se concentrar na redução das perdas de disponibilidade, desempenho e qualidade no âmbito de uma dada máquina ou linha, a conceituação do OEE ou OEEL pode ser efetivamente aplicada para balizar o planejamento e direcionamento de melhorias.

Já para se buscar um aproveitamento ainda maior da capacidade instalada, é preciso adotar ferramentas de medição que possam relacionar as influências de outras áreas da organização sobre a operação das linhas, da fábrica e da manufatura como um todo. Isso possibilita vislumbrar meios para reduzir as paradas planejadas e outras paradas causadas por fatores externos à competência da área operacional. No caso estudado, o OPEL e o OPE foram bem explorados com essa função, e isso propiciou que partes diferentes da cadeia de valor passassem a atuar de forma mais integrada e mais bem alinhada aos objetivos estratégicos da empresa. Vale salientar que esses dois indicadores são bastante afetados por tendências de mercado e das vendas, contribuindo para evidenciar o impacto das estratégias comercial e de marketing sobre o desempenho da produção.

Em relação à aplicação de indicadores agregados como OTE e OPE, como no segundo período do caso estudado, observa-se que os mesmos servem basicamente para informar à alta direção qual foi o nível de aproveitamento geral da capacidade no âmbito de uma unidade de manufatura. Ao final do segundo período, a alta direção da empresa já dispunha de dados de OTE e OPE não apenas da unidade focada no estudo de caso, como também de outras unidades controladas por ela. Isso tornou possível avaliar comparativamente o desempenho das diversas unidades, ajudando a obter uma visão estratégica da situação da manufatura no âmbito de toda a empresa.

Contudo, em fábricas constituídas por um conjunto de linhas como a da unidade analisada no caso, resultados de OTE e OPE não necessariamente refletem a situação de cada linha. Assim sendo, para subsidiar tomadas de decisão e direcionar a atuação dos gestores responsáveis por racionalizar o aproveitamento da capacidade, é indispensável manter a medição do OEEL e OPEL estratificada por linhas, como sugerem as Figuras 9 e 10. Tal visão possibilita enxergar a natureza da contramedida a ser priorizada, i. e. aumento do OEEL ou do OPEL, e para qual linha os esforços e recursos para melhoria devem ser direcionados, dada a variação de magnitude das perdas que afetam esses indicadores nas linhas consideradas. 


\section{Conclusão}

0 caso estudado ilustra como uma abordagem de gerenciamento mais sistêmico do sistema produtivo, balizada em indicadores globais como o OTE e OPE, favorece a concatenação de ações entre a manufatura, suas áreas de apoio e outras áreas da cadeia de valor para se obter uma utilização mais efetiva de seus ativos e contribuir na busca de resultados melhores ao negócio. Isso corrobora a proposta da utilização de indicadores mais abrangentes que o OEE quando o aproveitamento da capacidade torna-se crítica ao desempenho global de uma unidade de manufatura.

Independentemente do indicador medido, o resultado numérico por si só não passa de mera informação. 0 histórico de cerca de nove meses de uso sistemático do OEEL e OPEL como indicadores no primeiro período ilustra bem o grau de envolvimento que a gerência deve demonstrar para que, a partir das informações assim obtidas, ações de melhoria e controle sejam realmente desdobradas e desse modo conseguir que uma nova prática como essa seja consolidada.

A literatura que se baseia na conceituação do OEE para propor um indicador de desempenho mais abrangente, em geral, concentra-se na concepção de um determinado modelo de cálculo. Este artigo mostra que o projeto de um sistema de avaliação do desempenho global da manufatura não pode ficar limitado à seleção da melhor fórmula de cálculo a ser adotada na medição, já que a visão analítica requerida pode mudar com o tempo e as circunstâncias. 0 desafio reside, portanto, no estabelecimento de um processo que permita à organização identificar e selecionar um modelo de indicador com uma estrutura que se adapte bem à realidade e necessidades de seu sistema de produção e torná-lo operacional.

Para orientar a articulação de tal processo, este trabalho procurou destacar a importância dos seguintes pontos: 1. definição da abrangência (fronteiras) do sistema produtivo objeto de análise, 2 . definição do escopo da classificação de perdas que melhor se adequa à natureza das paradas que afetam as operações deste sistema, 3. seleção/adaptação de indicador(es) a partir das definições anteriores e implementação de um processo que os utilize efetivamente como ferramenta de gestão, e 4. estabelecimento de uma dinâmica de identificação/resolução de problemas que envolva representantes-chave das áreas relacionadas, sob a firme coordenação de um responsável pela melhoria contínua. A matriz elaborada na Figura 4, que serviu como pano de fundo na Figura 11, subsidia a busca de um indicador adequado em função dos pontos 1 e 2 enumerados acima.
Uma limitação deste trabalho reside no fato de que na unidade focada no estudo de caso, a variedade de produtos é pequena e as linhas são independentes, operando em fluxo contínuo unidirecional. A abordagem de medição aqui apresentada precisa, portanto, ser considerada com ressalvas e/ou adaptações no projeto do sistema de medição em sistemas produtivos mais complexos. Extensões do presente estudo podem ser desenvolvidas incluindo a consideração de aspectos como a variação dos roteiros de produção, organização do layout de equipamentos por processo (e não por produto) e a existência de estoques intermediários, que influenciariam a forma de ponderação e consolidação de dados na medição de indicadores globais.

\section{Referências}

BAMBER, C. J. et al. Cross-functional team working for overall equipment effectiveness (OEE). Journal of Quality in Maintenance Engineering, v. 9, n. 3, p. 223-238, 2003. http://dx.doi.org/10.1108/13552510310493684

BRAGLIA, M.; FROSOLINI, M.; ZAMMORI, F. Overall equipment effectiveness of a manufacturing line (OEEML) - an integrated approach to assess systems performance. Journal of Manufacturing Technology Management, v. 20, n. 1, p. 8-29, 2009. http://dx.doi. org/10.1108/17410380910925389

BOHORIS, G. A. et al. TPM implementation in Land-Rover with the assistance of a CMMS. Journal of Quality in Maintenance Engineering, v. 1, n. 4, p. 3-16, 1995. http://dx.doi.org/10.1108/13552519510105179

CHAND, G.; SHIRVANI, B. Implementation of TPM in cellular manufacture. Journal of Material Processing Technology, v. 103, n. 1, p. 149-154, 2000. http://dx.doi.org/10.1016/ S0924-0136(00)00407-6

FLEISCHER, J.; WEISMANN, U.; NIGGESCHMIDT, S. Calculation and optimisation model for costs and effects of availability relevant service elements. In: CIRP INTERNATIONAL CONFERENCE ON LIFE CYCLE ENGINEERING, 13., 2006, Leuven. Proceedings... Leuven, 2006. p. 675-680. Disponível em: <http://www.mech.kuleuven.be/lce2006/154.pdf>. Acesso em: 19 dez. 2011.

GAGNON, S. Resource-based competition and the new operations strategy. International Journal of Operations andProduction Management, v. 19, n. 2, p. 125-138, 1999. http://dx.doi.org/10.1108/01443579910247392

GIBBONS, P. M.; BURGESS, S. C. Introducing OEE as a measure of lean six sigma capability. International Journal of Lean Six Sigma, v. 1, n. 2, p.134-156, 2010. http://dx.doi.org/10.1108/20401461011049511

HÖGFELDT, D. Plant efficiency: a value stream mapping and overall equipment effectiveness study. 2005. 93 f. Master Thesis (Master of Science Programme - Mechanical Engineering)-University of Technology, Lulea, 2005.

JEONG, K. Y.; PHILLIPS, D. T. Operational efficiency and effectiveness measurement. International Journal of Operations and Production Management, v. 21, n. 11, p. 1404-1416, 2001. http://dx.doi.org/10.1108/ EUM0000000006223 
JONSSON, P.; LESSHAMMAR, M. Evaluation and improvement of manufacturing performance measurement systems - the role of OEE. International Journal of Operations and Production Management, v. 19, n. 1, p. 55-78, 1999. http://dx.doi.org/10.1108/01443579910244223

KWON, 0.; LEE, H. Calculation methodology for contributive managerial effect by OEE as a result of TPM activities. Journal of Quality in Maintenance Engineering, v. 10, n. 4, p. 263-272, 2004. http://dx.doi. org/10.1108/13552510410564882

LJUNGBERG, 0 . Measurement of overall equipment effectiveness as a basis for TPM activities. International JournalofOperations and Production Management, v. 18, n. 5, p. 495-507, 1998. http://dx.doi.org/10.1108/01443579810206334

MEREDITH, J. Building operations management theory through case and field research. Journal of Operations Management, v. 16, n. 4, p. 441-454, 1998. http:// dx.doi.org/10.1016/S0272-6963(98)00023-0

MIGUEL, P. A. C. Adoção do estudo de caso na engenharia de produção. In: MIGUEL, P. A. C. (Coord.). Metodologia de pesquisa em engenharia de produção e gestão de operações. Rio de Janeiro: Elsevier, 2010. p. 129-143.

MUCHIRI, P.; PINTELON, L. Performance measurement using overall equipment effectiveness (OEE): literature review and practical application discussion. International Journal of Production Research, v. 46, n. 13, p. 3517-3535, 2008. http://dx.doi.org/10.1080/00207540601142645

MUTHIAH, K. M. N.; HUANG, S. H. Overall Throughput Effectiveness (OTE) metric for factory-level performance monitoring and bottleneck detection. International Journal of Production Research, v. 45, n. 20, p. 4753-4769, 2007. http://dx.doi.org/10.1080/00207540600786731

MUTHIAH, K. M. N.; HUANG, S. H.; MAHADEVAN, S. Automating factory performance diagnostics using overall throughput effectiveness (OTE) metric. International Journal of Advanced Manufacturing Technology, v. 36, n. 7-8, p. 811-824, 2008. http://dx.doi.org/10.1007/ s00170-006-0891-x
NACHIAPPAN, R. M.; ANANTHARAMAN, N. Evaluation of Overall line Effectiveness (OLE) in a continuous product line manufacturing system. Journal of Manufacturing Technology, v. 17, n. 7, p. 987-1008, 2006. http://dx.doi. org/10.1108/17410380610688278

NAKAJIMA, S. Introduction to Total Productive Maintenance - TPM. Cambridge: Productivity Press, 1989.

OECHSNER, R. et al. From overall equipment effectiveness to overall Fab effectiveness (OFE). Materials Science in Semiconductor Processing, v. 5, n. 4-5, p. 333-339, 2003. http://dx.doi.org/10.1016/S1369-8001(03)00011-8

RAOUF, A. Improving capital productivity through maintenance. International Journal of Operations and Production Management, v. 14, n. 7, p. 44-52, 1994. http://dx.doi.org/10.1108/01443579410062167

RON, A. J.; ROODA, J. E. Equipment effectiveness: OEE revisited. IEEE Transactions on Semiconductor Manufacturing, v. 18, n. 1, p. 190-196, 2005. http:// dx.doi.org/10.1109/TSM.2004.836657

SAKAKIBARA, S. et al. Empirical research methods in operations management. Journal of Operations Management, v. 9, n. 2, p. 205-228, 1990.

SLACK, N. et al. Administração da Produção. 2. ed. São Paulo: Atlas, 2002.

STAUDT, F. H.; COELHO, A. S.; GONCALVEZ, M. B.; Determinação da capacidade real necessária de um processo produtivo utilizando cadeia de Markov. Revista Produção, v. 21, n. 4, p. 634-644, 2011.

SUZUKl, T. TPM in process industries. New York: Productivity Press, 1994.

TSAROUHAS,P.Implementation of totalproductivemaintenance in food industry: a case study. Journal of Quality in Maintenance Engineering, v. 13, n. 1, p. 5-18, 2007. http://dx.doi.org/10.1108/13552510710735087

WEE, H. M.; WU, S. Lean supply chain and its effect on product cost and quality: a case study on Ford Motor Company. Supply Chain Management: An International Journal, v. 14, n. 5, p. 335-341, 2009. http://dx.doi. org/10.1108/13598540910980242

\title{
An analysis of the application of indicators alternative to Overall Equipment Effectiveness (OEE) in the management of a plant's overall performance
}

\begin{abstract}
Despite the fact that the measurement of Overall Equipment Effectiveness (OEE) is an increasingly disseminated industrial management practice, indicators alternative to it have been proposed in the literature to cope with performance measurement at the higher level of production systems. The purpose of this article is to present such indicators and discuss their potential application in searching effective utilization of production capacity. Initially, a conceptual framework was built to arrange indicators that broaden the evaluation approach adopted by OEE. To analyze the application potential of indicators that present this function, a case study was developed in a foodprocessing firm. The case suggests that the application of indicators like Overall Throughput Effectiveness (OTE) and Overall Plant Effectiveness (OPE), besides making the diagnosis of capacity utilization problems more effective, can promote the integration of production strategy with other functional strategies, and thus promote a more effective management of a plant's overall performance.
\end{abstract}

Keywords

OEE. OTE. OPE. Performance indicator. Capacity. 
Anexo 1. Protocolos das etapas 1 e 2 do estudo de caso.

\begin{tabular}{cll}
\hline & \multicolumn{1}{c}{ Etapa 1 } & \multicolumn{1}{c}{ Etapa 2 } \\
\hline $\begin{array}{c}\text { Contexto a se } \\
\text { ter em mente }\end{array}$ & $\begin{array}{l}\text { Introdução de um sistema de avaliação do desempenho } \\
\text { global da fábrica com base na conceituação do OEE }\end{array}$ & $\begin{array}{l}\text { Aprimoramento e expansão do sistema de avaliação do } \\
\text { desempenho global da fábrica com base na conceituação do OEE }\end{array}$ \\
\hline \multirow{2}{*}{ Objetivo } & $\begin{array}{l}\text { Conhecer o sistema de medição do desempenho global } \\
\text { da fábrica em implementaça, a dinâmica de análise } \\
\text { dos resultados gerados pelo mesmo e a forma como as } \\
\text { açães de controle e melhoria são desdobradas }\end{array}$ & $\begin{array}{l}\text { Verificar a evolução do sistema de medição, avaliação e melhoria } \\
\text { do desempenho global da fábrica em desenvolvimento e seus } \\
\text { principais efeitos na organização desde a visita anterior }\end{array}$ \\
\hline
\end{tabular}

- Obtenção do apoio do coordenador de MCC para realização do estudo e definição da fábrica a ser abordada (unidade de análise)

- Por consulta prévia ao coordenador de MCC:

- Obter informações gerais sobre essa fábrica

Preparação (organograma, produtos, posição na cadeia, pré-visita negócio, tamanho)

- Identificar as áreas funcionais envolvidas no sistema de medição do desempenho na unidade de análise

- Solicitar agendamento de entrevistas com representantes destas áreas

- Agendar visita à fábrica

Na reunião de entrevista com os representantes das áreas envolvidas e o coordenador de MCC, seguir o roteiro semiestruturado abaixo:

- Registrar dados sobre cada entrevistado

- Levantar dados para caracterização geral da fábrica (processos, recursos etc.) e da conjuntura em que ela está inserida

- Inquirir sobre o sistema de medição e avaliação de desempenho introduzido:

- Finalidade do sistema

- Definição formal (fórmula) do(s) indicador(es) de desempenho aplicados

- Classificação das perdas consideradas

- Sistemática de coleta de dados e cálculo do(s) indicador(es)

Procedi-mento - Método de análise dos resultados

de coleta de dados no local

- Organização mobilizada na gestão do desempenho global da fábrica

- Obter exemplos de cálculo do(s) indicador(es) global(is) focado(s)

- Verificar a evolução do(s) indicador(es) e o histórico das principais ações desdobradas num período recente

- Inquirir sobre as principais ações desdobradas no período considerado no item 7: propósito, área(s) envolvida(s), resolução tomada

Além da coleta de dados por meio da reunião de entrevista:

- Realizar observação in loco das instalações da fábrica

- Obter dados históricos de produção e perdas no período considerado no item 7 e documentos complementares
- Obtenção do apoio do coordenador de MCC para realização de uma visita de retorno à unidade de análise

- Por consulta prévia ao coordenador de MCC:

- Obter informações gerais sobre a evolução do sistema de medição de desempenho da fábrica

- Identificar as áreas funcionais envolvidas na expansão do sistema de medição do desempenho global

- Solicitar agendamento de entrevistas com representantes destas áreas

- Agendar visita à fábrica
- Registrar dados sobre cada entrevistado

- Verificar se houve mudanças significativas na caracterização geral da fábrica desde a visita anterior

- Verificar se houve mudanças significativas na conjuntura de desde a visita anterior

- Inquirir sobre a expansão do sistema de medição e avaliação do desempenho global em desenvolvimento, procurando verificar mudanças em relação às dimensões $5 a, 5 b, 5 c, 5 d$, $5 e$ e $5 f$ desde a visita anterior

- Obter exemplos de cálculo do(s) indicador(es) global(is) incorporado(s) no sistema expandido

- Verificar a evolucão dos indicadores monitorados pelo sistema expandido e o histórico das principais ações desdobradas num periodo recente

- Inquirir sobre as principais ações desdobradas no período considerado no item 20: propósito, área(s) envolvida(s), resolução tomada mercado/negócio/corporativa em que a fábrica está inserida

11 (etapa 1), 24 (etapa 2). Elaborar relatório com dados descritivos levantados na visita e enviar ao coordenador de MCC

Estágio para validação

pós-visita 12 (etapa 1), 25 (etapa 2). Consultar o coordenador de MCC para esclarecimento de dúvidas que surgirem da reflexão pós-visita sobre dados e documentos coletados para a pesquisa

Abreviatura: MCC: melhoria contínua corporativo.

Anexo 2. Participação dos entrevistados nas atividades enumeradas nos protocolos do estudo de caso.

\begin{tabular}{|c|c|c|c|c|c|c|c|c|c|c|c|c|c|c|c|c|c|c|}
\hline \multirow[b]{2}{*}{ Entrevistado } & \multicolumn{9}{|c|}{ Etapa 1} & \multicolumn{9}{|c|}{ Etapa 2} \\
\hline & MCC & Prod & Man & Qual & $\mathrm{MCU}$ & PCP & P\&D & Mark & Com & MCC & Prod & Man & Qual & $\mathrm{MCU}$ & РCP & P\&D & Mark & Com \\
\hline $\begin{array}{l}\text { Preparação } \\
\text { pré-visita }\end{array}$ & 1,2 & - & - & - & - & - & - & - & - & $\begin{array}{l}13, \\
14\end{array}$ & - & - & - & - & - & - & - & - \\
\hline $\begin{array}{l}\text { Procedimento } \\
\text { de coleta de } \\
\text { dados no local }\end{array}$ & $\begin{array}{l}3,5 \\
\text { a } 8\end{array}$ & 3 a 9 & 3 a 9 & $\begin{array}{l}3,4, \\
7,8\end{array}$ & $\begin{array}{l}3 \mathrm{a} \\
10\end{array}$ & $\begin{array}{c}3, \\
7,8\end{array}$ & $\begin{array}{c}3, \\
7,8\end{array}$ & $\begin{array}{c}3, \\
7,8\end{array}$ & $\begin{array}{c}3, \\
7,8\end{array}$ & $\begin{array}{l}15, \\
17 \text { a } \\
21\end{array}$ & $\begin{array}{l}15 \mathrm{a} \\
22\end{array}$ & $\begin{array}{c}15 \mathrm{a} \\
22\end{array}$ & $\begin{array}{l}15 \\
16 \\
20 \\
21\end{array}$ & $\begin{array}{l}15 a \\
23\end{array}$ & $\begin{array}{l}15 \\
20 \\
21\end{array}$ & $\begin{array}{l}15, \\
20 \\
21\end{array}$ & $\begin{array}{l}15, \\
20 \\
21\end{array}$ & $\begin{array}{l}15, \\
20 \\
21\end{array}$ \\
\hline $\begin{array}{l}\text { Estágio } \\
\text { pós-visita }\end{array}$ & $\begin{array}{l}11 \\
12\end{array}$ & & & & $\begin{array}{l}11 \\
12\end{array}$ & - & - & - & - & $\begin{array}{l}24, \\
25\end{array}$ & - & - & - & $\begin{array}{l}24, \\
25\end{array}$ & - & - & - & - \\
\hline
\end{tabular}

Abreviaturas: MCC: melhoria contínua corporativo, Prod.: produção, Man.: manutenção, Qual.: qualidade, MCU: melhoria contínua da unidade, PCP: programação e controle da produção, P\&D: pesquisa e desenvolvimento, Mark.: marketing, Com.: comercial. 
Anexo 3. Dados utilizados no cálculo do OEEL e OPEL para a linha analisada (L2).

\begin{tabular}{|c|c|c|c|c|c|c|c|c|c|c|}
\hline & & & A & B & $\mathrm{C}$ & D & $\mathrm{E}$ & & & \\
\hline & Fase - mês & Semana & $\begin{array}{c}\text { Tempo } \\
\text { Total } \\
\text { (h) }\end{array}$ & $\begin{array}{l}\text { Perdas } \\
\text { que não } \\
\text { impactam } \\
\text { no OEEL } \\
\text { (h) }\end{array}$ & $\begin{array}{l}\text { Tempo de } \\
\text { Carrega- } \\
\text { mento } \\
\text { (h) }\end{array}$ & $\begin{array}{l}\text { Perdas de } \\
\text { Disponi- } \\
\text { bilidade, } \\
\text { Desempenho } \\
\text { e Qualidade } \\
\text { (h) }\end{array}$ & $\begin{array}{c}\text { Tempo } \\
\text { com Valor } \\
\text { Agregado } \\
\text { (h) }\end{array}$ & $\begin{array}{c}\text { OEEL } \\
(\%)\end{array}$ & $\begin{array}{c}\text { OPEL } \\
(\%)\end{array}$ & $\begin{array}{c}\text { Volume } \\
\text { (ton) }\end{array}$ \\
\hline \multirow{9}{*}{1} & \multirow{4}{*}{ Abril } & s01 & $168: 00$ & $63: 33$ & $104: 26$ & $36: 36$ & $67: 49$ & 64,9 & 40,4 & 244,2 \\
\hline & & s02 & $168: 00$ & $40: 20$ & $127: 39$ & $42: 13$ & $85: 26$ & 66,9 & 50,9 & 307,6 \\
\hline & & s03 & 168:00 & $55: 38$ & $112: 21$ & $42: 07$ & $70: 14$ & 62,5 & 41,8 & 252,9 \\
\hline & & s04 & 168:00 & $37: 39$ & $130: 20$ & $45: 48$ & $84: 31$ & 64,9 & 50,3 & 304,3 \\
\hline & \multirow{4}{*}{ Maio } & s05 & 168:00 & $39: 38$ & $128: 21$ & $44: 49$ & $83: 31$ & 65,1 & 49,7 & 300,7 \\
\hline & & s06 & $168: 00$ & $46: 21$ & $121: 38$ & $43: 22$ & $78: 16$ & 64,3 & 46,6 & 281,8 \\
\hline & & s07 & $168: 00$ & $44: 21$ & $123: 38$ & $42: 40$ & $80: 58$ & 65,5 & 48,2 & 291,5 \\
\hline & & s08 & 168:00 & $49: 15$ & $118: 44$ & $41: 11$ & $77: 33$ & 65,3 & 46,2 & 279,2 \\
\hline & \multirow{4}{*}{ Junho } & s09 & 168:00 & $45: 01$ & $122: 58$ & $44: 08$ & $78: 50$ & 64,1 & 46,9 & 283,8 \\
\hline \multirow{8}{*}{2} & & s10 & 168:00 & 44:05 & $123: 54$ & $42: 30$ & $81: 24$ & 65,7 & 48,5 & 293,1 \\
\hline & & s11 & 168:00 & $48: 48$ & 119:11 & $36: 50$ & $82: 21$ & 69,1 & 49,0 & 296,5 \\
\hline & & $\mathrm{s} 12$ & 168:00 & $61: 43$ & $106: 16$ & 29:09 & 77:07 & 72,6 & 45,9 & 277,6 \\
\hline & \multirow{5}{*}{ Julho } & $\mathrm{s} 13$ & $168: 00$ & $68: 16$ & $99: 43$ & $24: 44$ & $74: 58$ & 75,2 & 44,6 & 269,9 \\
\hline & & s14 & 168:00 & $62: 51$ & 105:08 & $26: 07$ & 79:01 & 75,2 & 47,0 & 284,5 \\
\hline & & s15 & $168: 00$ & $61: 17$ & $106: 42$ & $24: 58$ & $81: 43$ & 76,6 & 48,6 & 294,2 \\
\hline & & s16 & 168:00 & $61: 44$ & $106: 15$ & $23: 12$ & 83:02 & 78,2 & 49,4 & 298,9 \\
\hline & & s17 & 168:00 & $50: 44$ & $117: 15$ & $23: 19$ & $93: 56$ & 80,1 & 55,9 & 338,2 \\
\hline \multirow{9}{*}{3} & \multirow{4}{*}{ Agosto } & s18 & 168:00 & $53: 55$ & $114: 04$ & $24: 06$ & $89: 57$ & 78,9 & 53,5 & 323,9 \\
\hline & & s19 & 168:00 & $53: 13$ & $114: 46$ & $23: 52$ & $90: 53$ & 79,2 & 54,1 & 327,2 \\
\hline & & $\mathrm{s} 20$ & $168: 00$ & $45: 54$ & 122:05 & $23: 44$ & $98: 20$ & 80,6 & 58,5 & 354,0 \\
\hline & & s21 & 168:00 & $46: 42$ & $121: 17$ & $24: 40$ & $96: 37$ & 79,7 & 57,5 & 347,9 \\
\hline & \multirow{5}{*}{ Setembro } & $\mathrm{s} 22$ & 168:00 & 28:05 & $139: 54$ & $28: 16$ & $111: 38$ & 79,8 & 66,5 & 401,9 \\
\hline & & s23 & $168: 00$ & $25: 21$ & $142: 38$ & 29:08 & $113: 29$ & 79,6 & 67,6 & 408,6 \\
\hline & & s24 & 168:00 & $18: 51$ & 149:08 & $28: 27$ & $120: 40$ & 80,9 & 71,8 & 434,4 \\
\hline & & s25 & 168:00 & $17: 51$ & 150:08 & $27: 45$ & $122: 22$ & 81,5 & 72,8 & 440,6 \\
\hline & & s26 & $168: 00$ & $14: 17$ & $153: 42$ & $26: 35$ & 127:07 & 82,7 & 75,7 & 457,7 \\
\hline \multirow{13}{*}{4} & \multirow{4}{*}{ Outubro } & $\mathrm{s} 27$ & 168:00 & $13: 00$ & $154: 59$ & $30: 43$ & $124: 16$ & 80,2 & 74,0 & 447,4 \\
\hline & & s28 & 168:00 & $12: 01$ & $155: 58$ & $30: 12$ & $125: 46$ & 80,6 & 74,9 & 452,8 \\
\hline & & $\mathrm{s} 29$ & 168:00 & $12: 18$ & $155: 41$ & 28:09 & $127: 32$ & 81,9 & 75,9 & 459,2 \\
\hline & & s30 & 168:00 & $12: 12$ & $155: 47$ & $28: 48$ & $126: 58$ & 81,5 & 75,6 & 457,1 \\
\hline & \multirow{5}{*}{ Novembro } & s31 & 168:00 & $7: 56$ & 160:03 & $26: 47$ & $133: 16$ & 83,3 & 79,3 & 479,8 \\
\hline & & s32 & 168:00 & $7: 51$ & $160: 08$ & $26: 19$ & $133: 48$ & 83,6 & 79,6 & 481,7 \\
\hline & & s33 & 168:00 & $8: 17$ & $159: 42$ & 23:01 & $136: 40$ & 85,6 & 81,4 & 492,0 \\
\hline & & s34 & 168:00 & $7: 25$ & $160: 34$ & 21:09 & $139: 25$ & 86,8 & 83,0 & 501,9 \\
\hline & & s35 & 168:00 & $7: 27$ & 160:32 & $20: 46$ & $139: 45$ & 87,1 & 83,2 & 503,1 \\
\hline & \multirow{4}{*}{ Dezembro } & s36 & $168: 00$ & $8: 46$ & 159:13 & $22: 34$ & 136:39 & 85,8 & 81,3 & 492,0 \\
\hline & & s37 & 168:00 & $7: 56$ & 160:03 & $23: 33$ & $136: 29$ & 85,3 & 81,2 & 491,4 \\
\hline & & s38 & 168:00 & $8: 16$ & $159: 43$ & $20: 56$ & $138: 46$ & 86,9 & 82,6 & 499,6 \\
\hline & & s39 & 168:00 & $7: 53$ & 160:06 & $19: 31$ & $140: 34$ & 87,8 & 83,7 & 506,1 \\
\hline
\end{tabular}

Medição formal do OPEL introduzida na semana s18; Dados anteriores de OPEL da s01 a s17 foram projetados pelos autores;

Fórmulas: $\mathrm{OEEL}=\mathrm{E} /(\mathrm{A}-\mathrm{B})=\mathrm{E} / \mathrm{C}$ e $\mathrm{OPEL}=\mathrm{E} / \mathrm{A}$ 